\title{
Expression of Concern: Potential Risks and Unknown Effects of mRNA Vaccines On Population Health ( $5^{\text {th }}$ Rev.)
}

Jianqing Wu, Ph.D., J.D.

Written on Mar 17, 2021; revised many times and submitted for publication

Correspondence: tempaddr2@atozpatent.com

1. Healthier World (Independent researcher for cause), P. O. Box 689, Beltsville, MD 20704. www.igoosa.com.

Keywords: mRNA vaccines, SARS-CoV-2, COVID-19, coronavirus, population vaccination, vaccine risks

\begin{abstract}
Several mRNA vaccines are used on the population in the U.S. My prior simulation study and model study enabled me to identify many flaws in clinical trials, side-effect evaluation methods and mechanism studies. Persons have organs' functional reserves, which could be from a few percents to many times of the minimum functions necessary for sustaining life. It is an indisputable fact that drugs and chemicals can slowly damage cells and tissues without causing any symptoms. To find a better approach to assessing vaccine risks, I consider failure in predicting drug side effects in product liabilities and removals of FDA approved drugs. Based on evidence I have found, I conclude that the risks of vaccination cannot be determined by experiments alone and must be determined by using a combination of methods. By studying mRNA expression dynamics and kinetics, I predict that vaccination with mRNA vaccines may increase cancer risks by affecting the Central Nervous System, interfere with normal protein synthesis, dramatically disrupt the normal immune system, alter the normal selection process for viral evolution resulting in more virulent viruses, and aggravate chronic diseases or cause them to relapse. Two root problems are practical inability to control expression sites, and expected severe adverse reactions from repeated vaccination, particularly, booster shots. Off-target expressions may result in unknown health effects while the severe adverse reactions pose unreasonable risks on persons whose vascular functional reserves are relatively small, or whose vascular systems are temporarily burdened by other causes such as viral infections or life activities. If an mRNA vaccine is administered on a pregnant women by second or booster shots, spike protein synthesis in fetus brain disrupts the highly regulated protein synthesis processes, resulting in potential brain damages. I found that the actual number of deaths caused by mRNA vaccines has been grossly underestimated.
\end{abstract}




\section{INTRODUCTION}

When this first drat was posed on open science servers, there was little direct evidence on the adverse effects of mRNA vaccines. The primary supporting evidence is mRNA vaccines adverse reactions reported in the CDC VAER database [1]. However, the reported symptoms in the database raise many questions about the safety of the mRNA vaccines. I cannot accept the similar arguments in medicine. The reason is that I have found two fatal flaws in clinical trials: None of health properties follows any well known statistical distributions even though sometimes the observed numbers may happen to have a bell-shaped profile, the second problem is that none of the health properties can be added and averaged as they are routinely used in medical research [2-3]. Per our prior study, health condition, death rate, ability to resist diseases, etc. are not the kind of properties that can be added up like weight and volume. The death rate of a twenty years old healthy person and the death rate of a ninety years severely ill person are completely different in all important attributes. Thus, all means used in population studies are products in violation of this forbidden rule. The biggest flaw is use of symptoms to determine side effects. This method has been refuted by overwhelming post-1980 studies, which have consistently found that drugs, chemicals, heavy metals, natural compounds, etc. can damage cells and tissues without causing any symptoms. The findings in the last half a century thus cast serious doubt on the utility of clinical data.

To see the flaws in the research model for studying latent effects, it is necessary to review personal injury case reports for asbestos, Dichloro-diphenyl-trichloroethane (DDT), Diethylstilbestrol (DES), lead paints, and prescription drugs. Lead has hurt humans for the longest time [4-5]. It was the key element in lead utensils. Based on personal knowledge, ancient lead wine pots were still popularly used in some nations even in 1970s. However, as early as in 1786, Benjamin Franklin wrote a letter warning a friend about the hazards of lead and lead paint, which he considered well-established [4]. The U.S. Consumer Product Safety Commission banned lead paint in 1977 in residential properties and public buildings, along with toys and furniture. Asbestos was known to have adverse health effects in 1899 and the first documented death related to asbestos was in 1906, but EPA made its attempt to ban asbestos in 1991 [6]. It took nearly a century to finally dispel doubts in its harmful effects. DDT was developed as the first synthetic insecticide in the 1940s and was disused after 1971. It was once widely used for more than three decades [7]. The Orange Agent (herbicides, 2,4,5-T and 2,4-D) was discovered in 1943 and was used between 1962 and 1971 in Vietnam, Laos and Cambodia [8]. Even in 2006, studies still lacked consensus on the adverse health effects [8] and the last update published in 2016 by National Academy of Medicine found that it is associated with soft tissue sarcoma, non-Hodgkin lymphoma, Hodgkin disease, chronic lymphocytic leukemia (including hairy cell leukemia) and other chronic B-cell leukemias. The Orange Agent controversy lasted about seven decades. DES was discovered in 1938 and introduced for medical use in 1939. The move was like speed of light for a drug. In 2011, it was generally agreed that DES was linked to infertility, miscarriage, ectopic pregnancy, preeclampsia, preterm birth, stillbirth, infant death, menopause prior to age, breast cancer, cervical cancer, and vaginal cancer [9]. DES controversy lasted for nearly seven decades before its severe adverse effects were finally determined. Roundup (with an active compound of Glyphosate) was developed and patented in the 1970 s and marketed from 1973. Despite 
the careful review by multiple agencies of nearly 800 research articles conducted in about four decades, it has escaped early detection of its carcinogenic effect. As of October 30, 2019, there were over 42,000 plaintiffs who sued for the cancer caused by glyphosate herbicides [13-14]. The inability to determine latent product/drug harmful effects is not exceptional but repeating reality. There are a large number of FDA-approved drugs that have been removed for subsequently discovered side effects [12].

It took three decades to a century, with the longest time being thousands of years to finally determine latent harmful effects of dangerous products and drugs. DES mimics a female hormone and there is no plausible mechanism to predict its severe adverse impacts: a few DES pills could ruin a female user, her daughter and the babes of the daughter. The inability to find latent side effects is due to the extreme complexity of the human body or life. I found that latent side effects are always concealed by the massive organ reserves [15-18] and thus symptom-based research models are clearly unworkable. A healthy person only needs $30-40 \%$ of maximum functional capacity to feel well [15-18], but a drug, vaccine or treatment could consume organ functional reserves without causing any symptoms. Moreover, functions of each of vital organs are controlled and influenced by a large number of lifestyle factors [23]. Thus, experiment-based research models lack required accuracy for resolving the contribution of any weak or slowly-delivering effect of a factor from other factors. The use of statistical analysis to "write off" all weak factors is clearly a wrong approach to health problems [2-3]. By recognizing multiple factors interactions and a high accuracy requirement, one must find that all key presumptions: statistical distribution, separation between mind and body, use of mathematical models, use of binary scale, etc. are deeply flawed [3]. In addition, chronic injuries nearly always develop very slowly, it would be impossible to find culprit drugs, chemicals or treatments due to limited trial duration. The dispute in cancer risks (as between studies 13 and 14) is thus meaningless until fundamental flaws are fully addressed.

Considering all of the reasons stated above, true risks of mRNA vaccines cannot be based on clinical trial data and nor findings of experiment-based research data. Their risks must be assessed by non-experimental methods such as theoretical model with experimental data being used as model parameters.

\section{KNOWN RISKS AND OTHER UNKNOWN EFFECTS}

\section{A. Vaccines' Severe Adverse Reactions}

The first report of the successful use of in vitro transcribed (IVT) mRNA in animals was published in 1990. Up until 2020, biotech companies had poor results testing mRNA drugs for cardiovascular, metabolic and renal diseases, cancer, and rare diseases, with most findings that the side-effects of mRNA insertion were too serious. mRNA vaccines for human use have been developed and tested for the diseases rabies, Zika, cytomegalovirus, and influenza, but these mRNA vaccines have not been licensed for use [19-21]. Many large pharmaceutical companies abandoned the technology. The Pfizer/BioNTech and Moderna COVID-19 vaccines seem to be the first mRNA vaccines used on human population [22-23]. The vaccines were rushed out in less than a year rather than normally required 7 to 10 years. 
The vaccination method does not comport with the normal disease process in evolution, but introduces foreign mRNA into cells where the mRNA produces proteins. There are many potential risks that have not been fully studied. Concern with severe adverse reactions of mRNA vaccines is reflected in the history of vaccine development [19-21]. The adverse effects of the vaccines may be severer than natural infections in various situations (See FIG. 1). Disease severity of a person is a varying property, which depends on the level of exposure and the personal immune system. All natural disease processes generally follow a progressive curve from "nothing to the maximum", as shown in (B) in FIG. 1. In any natural disease course, an infectious agent always starts with one, a few, or a small number to reach a level that impairs organ functions. It is anticipated that the body must immobilize its immune resources to contain the infectious agent from spreading. This kinetic feature determines that humans ordinarily can weather infectious agents and progressive viral replication course cannot be very radical. In contrast, vaccines, even at seemingly low injection dosages, always deliver much more molecular number to achieve severer adverse reactions as shown in $(A)$ in FIG. 1, as compared with the viral copies that a person could be exposed to in the initial stage. It is very possible that the vaccine's adverse reactions are severer than the disease in at least a fair portion of persons.

I question the very basic logic of using mRNA vaccines. The purpose of using vaccines is to accept mild adverse reactions in exchange for immunity or diminished severity of a future infection. However, vaccination with mRNA is like accepting strong adverse reactions in exchange for reduced severity of future infection, which may be very weak among at least $80 \%$ the population [60-62]. This poor trade can be justified only if the vaccine does not cause long-term damages to vaccine recipients.

I have examined original reports from vaccine report database for mRNA vaccines [1]. The following symptoms reflect the vaccine's adverse effects on the Central Nervous System: brain death, brain injury, cerebellar stroke, cerebral arteriosclerosis, cerebral artery embolism, cerebral artery occlusion, cerebral artery stenosis, cerebral artery thrombosis, cerebral atrophy, cerebral haematoma, cerebral infarction, cerebral microhaemorrhage, cerebral small vessel ischaemic disease, cerebral thrombosis, cerebral venous sinus thrombosis, cerebrovascular accident, encephalitis, paralysis, seizure, facial paralysis, Bell's palsy, headaches, nausea, vomiting, loss of consciousness, depressed level of consciousness, confusional state, disorientation, disturbance in attention, delirium, mental status changes, abnormal behaviors, anxiety, depression, diplopia, lethargy, mental impairment, insomnia/sleep disorder, abnormal dreams, disorganised speech or speech disorder, communication disorder, abnormal sensation in eyes, blurred vision, visual impairment, blindness, deafness, tinnitus, burning sensation, balance disorder, gait disturbance, decreased mobility, movement disorder, muscle spasms, restlessness, tremor, vertigo, dementia, impaired work ability, etc. Many symptoms may be due to local effects and problems in brain. Most people have multiple symptoms while the report accepts only three symptoms.

Those who have reported their symptoms must have experienced sufficiently severe adverse reactions. Severe symptoms are often reflected in descriptions and a large number of death cases. In addition, I also read from web blogs about personal experiences: some vaccine recipients have felt various problems for many days. In all those severe cases, I must assume that the vaccines have temporarily depressed their organ functions to nearly disability 
levels. For those who must be hospitalized, at least one vital organ function might fall to near the thresholds of death or disability. From my extensive observations, I noted that a large number of strong adverse reactions cannot be fully recovered.

\section{B. Flaws in Symptom-based Side Effects Evaluating Method}

I show that the symptom-based causation approach is deeply flawed. The acceptance of symptoms-based causation model in medicine was inevitable before the large organ functional reserves and toxins' working mechanisms were discovered. Without understanding the roles of organ functional reserves, one would naturally assume that any side effects must appear shortly after an exposure in a manner like "seeing symptoms after exposure". That is the most probable reason that lead was able to hurt mankind for thousands of years. This flawed approach has dominated all medicine systems for the entire human history, but has been refuted by our model based on post-1980 research discoveries [2-3], discoveries of organ's functional reserves [15-17], and cellular damage mechanisms [5, 13]. It has been found that many biological resources are redundant by huge margins (1 to more than 100 times): the person could survive by using only a 1 unit, but his body may have the ability to provide 100 times of that [18]. The problem of the symptom-based side effect evaluation approach is best reflected in lead toxicity. Lead exposure can cause widespread damages in cellular level including changes in gene and protein expression [5]. Since damages take place gradually, the slow changes in cells and tissues cannot instantly depress vital functional capacities because most people have massive surplus vital functional capacities (See FIG. 2). As shown in FIG. 2, people have great differences in vital functional capacities, as shown in A, $B$ and $C$. Earliest symptoms of latent side effects occur several years to many decades after exposure, depending on exposure level and personal health. In cases involving exposure to pesticides, the latency period is more than 10 years [97]. Symptoms-based prediction would be useful only for people without redundant organ functions. Thus, using distinctive symptoms to find disease causes or causal factors are improper for nearly all culprits. For example, lead damages are not confined to one kind of cells, one single organ or a unique body part, damages must be widespread and systemic [4-5]. The symptom-based side-effect evaluating method cannot survive over a large number of factual findings revealing widespread cellular damages caused by heavy metals [5, 86-87], drugs [9], substances [6, 80-81], plastics [88], synthetic chemicals [7-8, 10-11, 13-14, 90-105], unbalanced nutrition [83-85], etc. The appearance of the first symptoms are only the earliest signs that tend to appear in the earliest time in a large portion of exposed persons. A generalized observation is that cytotoxicins, carcinogens, neurotoxins, etc. can adversely affect a broad range of cells and tissues. While earliest signs may appear in certain organs or parts, there is no basis to preclude widespread cellular damages in other body parts. The last point is that latent side effects can be inflicted without causing any subjective signs if exposure is chronic and of limited intensity. Evidence in support of this observation is the fact that prescription drugs and industrial chemicals can cause long-term injuries to personal health without causing any sign of discomfort in the early stages of exposures [80, 82, 84-88, 91, 101, 103].

\section{Expected Adverse Effects on the Central Nervous System}

I predict that the mRNA vaccines will increase the risks for all kinds of CNS diseases including autism and mental disorders. This prediction is made by regarding all reported CNS problems as the manifestation of vaccines impacts on the CNS. This prediction is based on 
two propositions: rejecting symptom-based causation approach and disregarding distinctive symptoms. Massive organ surplus functions and the slowness in delivering latent side effects further impair the ability to find vaccines' long-term side effects. Those two problems are further complicated by a large number of lifestyle and activities factors. The massive number of reported mRNA symptoms indicate that mRNA's effects are both systemic and nondistinctive. Thus, a sound analysis should not be limited by known symptoms determined by flawed disease classifications. The elevated high incidence of Bell's palsy implies the possibility that mRAN vaccines are able to damage visual nerves, sensory nerves, and any part of the brain. The large number of non-distinctive vaccine symptoms reported in the CDC VAER database or web blogs cannot be "written off" as having nothing to do with vaccines.

The prevalence of autism spectrum disorder (ASD) in children in the U.S. is about three (3) times of the median in most nations [25]. I would attribute this high ASD rate to widespread use of vaccines in the U.S. [45-47]. ASD actually consists of a spectrum of brain disorders that are caused by a large number of causal factors in various combinations. They are influenced by genetic disorders, exposure to toxic substances, parent age, diabetes, bleeding, pre-pregnancy obesity, etc. [24-25]. Clearly, CNS diseases like ASD cannot be based on the symptoms-based causation model. A retrospective cohort study found that Bell's palsy and paraesthesia risks increase, and the risks of paraesthesia and inflammatory bowel disease among those vaccinated in the early phase (within 45 days) of the vaccination campaign were significantly increased [47]. Massive CNS symptoms from CDC VAER database refute the validity of symptom-based causation model for vaccines. It has been found that Bell's palsy in the vaccine arms is between 3.5-times and 7-times higher than would be expected in the general population [26]. This fact also indicates that the vaccines have adverse effects on the brain or nerves or both. Bell's palsy attracted researchers' attention because it causes obvious signs on face; however, due to random nature of offtarget expression, mRNA vaccine-induced damages are expected to affect any part of the brain and nerves although they may not attract attention from researchers. One mechanism of causing ASU is disrupting synapse connections by mRNA vaccines (see Section J). All reported CNS symptoms, increased risk of Bell's palsy, increased risk of autism (as collaborated by impacts of influenza vaccines), mRNA's disruption to synapse connections form a concordant evidence for predicting the adverse impacts of mRNA vaccines on the CNS. There is no basis to imagine that all of the massive reported CNS symptoms are harmless and can be fully recovered. Thus, I predict that mRNA vaccine may cause a wide range of CNS diseases including autism spectrum disorders and Bell's palsy. Moreover, human brain has very large functional redundancy. Destroying a few percents of neurons without causing localized tissue damages probably will not be felt, nor detected. Actual damages in most recipients will be felt only after the brain is unable to meet the required function. The increased prevalence of Alzheimer's disease may be partially caused by vaccinations.

\section{Incidental Burdens of Vaccine Adverse Reactions on Vital Organs}

Another bad problem arises from interactions between vaccines, COVID-19 disease, and other diseases. This interaction problem can be a serious issue when vaccination is conducted during an active pandemic. A person has a maximum vascular functional capacity, but could survive with only $40 \%$ of the maximum, and still survive even at $30 \%$ of the maximum [15, 17-18]. The only organ's function that can be conveniently monitored is the 
vascular function. The vascular system's surplus (unused) functional capacity could range from a few percents to more than $400 \%$ (which can be inferred from vascular functions as in 15, 17-18). That implies that personal vascular functional capacities could differ by as much as 100 times between a super strong person (as indicated by D in FIG. 2) and a person near death (as indicated by M in FIG. 2). FIG. 2 shows how infection and vaccination can burden vital organs by both acute injuries and latent injuries (which may reside on the curves). The cytokine storms of the infection and vaccine can add burdens to vital organs. Whether a person can survive from infection/vaccination depends on if the burden from the vaccination/infection is still within the maximum vital functional capacities. If the person has the maximum capacity at $D$, the person can survive cytokine storms V1 to V4. If the person's maximum vital functional capacity has been reduced to $B$ due to aging and preexisting diseases, etc, the person can survive from vaccine storms V1 or V2, but cannot survive from vaccination storms V3 or V4. However, vaccination as well as toxic substance can also cause the person to reduce the vital functional capacities by latent side effects. Vaccination-induced inflammation is like disease-induced inflammation, and thus must cause organs to lose functional capacity due to damages that are not reversed. If a person is frequently vaccinated, his vital functional capacities will be slowly reduced from $D=$ Max to $C, B, A$ and $M$ (The Minimum value).

The massive differences in personal vascular systems imply that conclusions from a clinical study cannot be applied to any of real persons. The risk of vaccines on each person must be addressed by focusing on the person's condition. Each of organ's functions is maintained by biological resources such as enzymes, DNA molecules, cells, and tissues, etc. A person can live without noticeable problems even if biological resources in support of vital functions have been reduced from 100 to 1.5 on a relative scale. However, the person will experience health problems if any other illnesses, toxic substances, environmental effects, or medical treatments further reduce the biological resources to less than 1 or what is required for maintaining life. No experimental study is able to determine how vaccines, drugs and natural infections consume biological resources in clinics, and the precise manner in which vaccine adverse effects superimpose on the effects of other diseases or toxic substances' effects. This problem cannot be investigated by a population trial but must be done by theoretical modeling for the person.

If a person receives vaccine injection during the latent period of a unknown SARS-Cov2 infection, the vaccine's adverse reaction and COVID-19 disease process will jointly burden all organ functions, particularly the heart function. The worse problem can happen when the peak of vaccine-induced cytokine storm and the perk of COVID-19 cytokine storm happen to overlap, as shown in FIG. 3. In this case, the vaccine may cause death of the patient who otherwise would not. The CDC VAER data clearly reveal that many mRNA recipients are COVID-19 positive around the time of receiving vaccine shots. I can see a scenario that viral infection could be very mild from inhaling a small number of SARS-Cov-2 gene copies, and it would take two or more days to develop enough symptoms. In this time window, the viral infection may be slowly activating the immune response against spike protein. Thus, injecting vaccines at this time window could cause the body to produce a large number of spike protein to cause a strong adverse reaction. In the worst scenario, the vaccine-induced reaction peak is in overlap with the virus-caused peak. This could be the worst because vaccine-striking sites are generally different from viral infection sites and thus can jointly raise the overall blood 
flow resistance; and, in addition, the proceeding viral infection could raise the white blood count in the blood stream and also make the immune system more reactive. Now, the mRNA vaccine is forcefully introduced at relatively high doses in a few seconds, this is not a scenario where the immune system is able to keep the spike protein from entering the body. The vaccination must cause very strong immune response in a very short time. Thus, I must attribute such a death to the vaccine as the primary cause of death while the COVID-19 infection may be secondary or even negligible. Due to smaller particle sizes, mRNA vaccines could reach any part of the body while SARS-Cov-2 virus targets mainly cells with ACE2 receptors [110].

It is reported that, Aix-Marseille University Faculty, Dr. Hervé Seligmann and engineer Haim Yativ, claim that Pfizer's shot causes "mortality hundreds of times greater in young people compared to mortality from coronavirus without the vaccine, and dozens of times more in the elderly, when the documented mortality from coronavirus is in the vicinity of the vaccine dose, thus adding greater mortality from heart attack, stroke, etc." [27]. Our theoretic prediction is highly consistent with their findings. Given the very strong peak of the vaccine induced reactions as experienced by a high percent of recipients, one hundred times rise in death rate is completely within my expectation. The real problem is that by using flawed symptom-based research methods, researchers can conveniently "write off" a large number of vaccine-induced deaths.

Heart seems to be the primary target organ injured by mRNA vaccines [28, 71]. After injection, particularly if the injection needle is close the large veins, some mRNA particles must get into the main blood circulation and some of mRNA particles get into heart muscles, where they cause spike protein synthesis. Thus, heart muscles are like accumulators of survival mRNA molecules. They keep producing spike protein until all mRNA particles in blood have been broken down. The extent of damages caused by mRNA vaccines in vaccinated recipients cannot be determined by clinical trials. This mechanism further supports Seligmann and Yativ finding that mRNA vaccines dramatically increased death rate among COVID-19 infected recipients.

In addition, noted symptoms, erythema multiforme, a form of allergic skin reaction, glomerulonephritis or kidney inflammation, and nephrotic syndrome [71] must add burden to the heart. Allergic skin reaction must dramatically raise local blood flow resistance and, similarly, diminished kidney functions can aggravate low-grade systemic inflammation due to accumulated metabolic by-products and thus raise blood pressure. When impacted tissues are widespread, those inflammations can cause heart failure.

\section{E. Increase Cancer Development Speed}

The old argument that mRNA vaccine cannot alter cell genetics is not relevant to cancer development speed. Nearly all prior predictions -- in the number hundreds to thousands of drugs and chemicals -- were finally proved to be wrong. The repeated failure implies that wrong results are not isolated incidents, but are due to systematic biases of symptom-based research method, and the poor accuracy of population research model. When a model could not explain so many risk and interference factors, the prediction by using such model is unreliable. The multiple factors model indicates that human body is so complex that many aspects of the body cannot be represented by mathematical models, descriptive models, physical systems, etc. [2-3]. Based on a large number of post-1980 studies, one must 
find that cancer development speed depends on a large number of factors, particularly, the CNS [29]. Cancer risks have been found to rise dramatically in following situations: chronic stress can cause release of excessive stress hormones and impair anti-tumor immunity; DES can elevate the risks of getting many types of cancer by interfering with female hormone metabolisms; glyphosate increases the risks of getting many types of cancer [93-99] possibly by impairing hippocampus [90] and impairing the immune system [91]; psychotropic drugs can raise many types of cancer risks obviously by interfering with CNS [30]. I found overwhelming evidence that CNS controls body's biological processes and tissue integrity [29]. In the last fifty years, medical researches have generated a large body of evidence that CNS affects human immune system including anti-tumor immunity. In all those cited cases, increased cancer risks are not realized through genetic mutation, but through compromising the immune system. Since vaccines can impair CNS by overwhelming adverse effects discussed in Sections A, C and J, I predict that vaccines promote cancer growth rates even though they may in some instances cause some types of cancer to self resolve by accident. In addition, altered cell behaviors can often continue to exist as if they were recorded in tissue memory or CNS memory. It is possible that mRNA may cause epigenetic changes, which can remain in the diseased tissue permanently.

\section{F. Adverse Effects from Disturbing the Immune System}

Vaccines' adverse effects through immune overload must be re-investigated in light of the flaws in the research model. Conclusions from population studies must be questioned or even rejected. Their true impacts can be predicted by examining their impacts on the immune cell population and their effects on the vascular system. It is known that B cells are antigensspecific. Thus, generation of excessive B cells (thus a higher plasma concentration) by repeated vaccination must alter this balance. The importance of this balance cannot be appreciated unless we focus on its long-term effects. Vaccination must cause excessive B cells population OR insufficient B cells population for any given disease pathogen. Excessive $B$ cells level must raise systemic blood pressure. By looking at both two limits, there must be an optimal point. I must say that excessive acquired immune responses are not good (even though there are instances that a specific immune response may produce incidental benefits). The existence of those limits are similar to stress hormones and female hormones (as found in DES injury cases).

An excessive number of immune cells in blood is the primary cause of lung tissue damage [31]. One big problem is that the capillary pores $(\sim 6 \mu \mathrm{m})$ are much smaller than most immune cells $(10-20 \mu \mathrm{m})$. When the body has an excessive number of immune cells, they can dramatically raise local and systemic blood pressures. A big blood pressure spike could result in heart failure, stroke and thrombosis. If the total number of B cells is limited, each type of B cells for a given antigen may be insufficient. In addition, I found that the excessive nonfunctional B cells and other immune cells must interfere with the functional B cells for fighting a given infection pathogen. From those limits, I concluded that acquired immunity may be intended as the last line of defense when early stage innate defense mechanisms fail to work. Running acquired immune responses at excessively high frequency cannot be a good thing. Non-deadly diseases should be better controlled by innate immunity at the early stage without triggering meaningful B cells differentiation and antibody production. The true adverse impacts of excessive and abusive vaccinations may depend on individual person's conditions and cannot be predicted by extending a population finding [2]. Some persons may be able to 
survive from endless vaccine shots, but some may be unable to survive from one single shot (see discussions for FIG. 2). Statistical analysis does funny averaging and produces averaged means that have no bearing on specific persons. The failure to recognize dangers of over reactive immune system should be attributed to the population approach which is incapable of studying immune dynamics for a person.

\section{G. Interference with Viral Evolution and Thus Create More Virulent Variants}

Past successful vaccinations become incentive to seek vaccines for every infection disease. However, it was suggested in a 2015 research article that vaccination can select for higher virulence [32] and this risk is unique for imperfect vaccines [33]. Those findings are consistent with general evolutionary rule [34]. The vaccination for the COVID-19 disease is different from other diseases in two aspects. First, SARS-CoV-2 virus is not a genetically stable antigen. By 2021, one leading site has collected more than a million SARS-CoV-2 sequences [35]. It can generate one new virus in about 11 to 15 days in an infected person. If we consider the total number of infected persons, the potential number of variants generated in their disease courses is very large; and since most new variants cannot be detected and sequenced, the actual number of viral variants is much larger. A large number of variants could be variants of concern [36]. Second, mRNA vaccines cannot produce full immunity mainly due to unique lung structure [37] and temperature effects on the immune system [38]. Thus, vaccination with mRNA vaccines must become a selection pressure promoting viral evolution. A population vaccination campaign will promote the virus to generate more virulent variants.

What makes the situation worse is a well known observation that viral infectious power can be increased by variants [39-42]. When multiple variants exist in the host, they can become more virulent. It may create a situation that a large number of people carry the virus which is mutating to generate different variants. Many of the infected people, who believe they are disease-free, may get close to each other and thus cross-infect each other. Some of them may get several variants. When multiple variants are present in the same person, they are more virulent. Repeated vaccination by using imperfect vaccines may promote viral evolution. This effect is predicted to be very similar to use of antibiotics: In the early years, antibiotics were very effective for controlling bacteria infection, but now it is more difficult to control bacterial infection [43]. In addition, co-infection by influenza viruses may also increase the infectious power of SARS-CoV-2. Thus, reliance on imperfect vaccination will create more obstacles in the long battle against the pandemic. The most recent study has shown that vaccination actually weakens personal anti-viral response even though it also reduces "nominal" death risk from COVID-19 [44]. Those risks must be considered together with widely used influenza vaccines, which are also imperfect vaccines [45-47].

There is a subtle reason to pay attention to genetic mutation which could be caused by mRNA vaccines. Genetic mutation is a very popular natural phenomenon. However, newly created genetic materials in species are controlled by the rule set in evolution. Most of altered genetic materials will disappear upon death of the host. When imperfect vaccines are not available, people must seek more natural measures for survival. There are ample measures $[37-38,49]$ that would improve the population's ability to weather the disease. However, when the population has heavily relied on mRNA vaccines, they make less efforts to seek natural remedies to improve their innate immunity and to learn basic skills for avoidance. Excessive 
disruptive interventions may disturb the subtle balance set in evolution.

Attempts to cure diseases by directly interfering with human biological processes have not achieved real success [2]. When billions of humans use this unnatural way as the primary anti-pandemic measure, its long-term impacts, if happened at all, could be the worst nightmare in the human history.

\section{H. Risks Attributing to Vaccine Distribution, Target Selection, and Expression}

mRNA is very unstable and thus requires strict storage and transportation condition. Any stability problems cannot be tolerated for mRNA vaccines. When an mRNA vaccine is in mass production, it would be difficult to maintain required quality [19-21, 52-54]. The high stability requirement for mRNA vaccines is similar to other kinds of vaccines. Several incidences were reflected in an influenza vaccination that caused 9 deaths within a day of receiving vaccines. When the mRNA vaccines are used on a large population, it would be hard to avoid storage and transportation problems.

Since mRNA can be degraded by enzymes in blood and tissue, mRNA molecules must be protected by suitable means so that they will not be broken down during their trafficking after injection [52-53]. mRNA vaccines have strands of mRNA chain inside a special lipid coating. The lipid coating protects the mRNA from being broken down by enzymes in the body. The coating also helps mRNA to enter the dendritic cells and monocytes (macrophages) in the lymph node near the injection site. It is expected that after injection, ongoing generation of vaccine-specific CD4+ T cells occurred only in the vaccine-draining lymph nodes, where detection of mRNA-encoded antigens peaked at 24 hours, whereas the antibody responses were sustained for weeks. Based on those time windows, I must assume that the "disease" course by vaccines is both strong and lasting. To reach the peak in 24 hours, the process must have a very fast responsive character like a rapid infection process. The long lasting nature of antibody implies that vaccinated persons are vulnerable to other disease attacks in the large time windows.

After intramuscular injection is done, the systemic trafficking of mRNA is detected. The mRNA are being destroyed during circulation. A large number of studies investigated the cellular entry of nucleic acids of various types of DNA and RNA [19, 52]. The molecules traveling in blood enter cells by diffusion controlled mechanisms or diverse endocytic processes, often strongly dependent on the respective cell type or species and frequently showed a vesicular localization, i.e., an entrapment in endocytic or lysosomal compartments [55-57]. Laboratory studies reveal that uptake of naked mRNA is a widespread phenomenon among primary cells and cell lines of diverse types. mRNA uptake depends on primary cells and cell lines, dose, temperature, caveolae or lipid rafts, scavenger-receptor(s), presence of macrophages and dendritic cells, etc. Moreover, different mRNA may use different routes and follow different uptake kinetics. mRNA uptake and expression in the human body is much more efficient than spontaneous uptake by cells in cell culture. Hydrodynamic pressure may force mRNA to enter cells in the case of local injections. A large number of mRNA appears to stay trapped in endosomal vesicles. Those findings show that mRNA uptake cannot be reasonably controlled in the human body.

The systemic distribution and expression of mRNA in different parts of the body could generate systemic cytokines, complement activation, unpredictable or undesirable effects or 
immune response. Among all studies reflected in the large reviews [19-21, 52-57], no study has explored two fundamental flaws in the mRNA vaccine technologies. First, none of the studies has addressed the deviation in the coating or varying local delivery environment. The average thickness of coatings or their protection times must follow a bell-shaped distribution. The relative protection or thickness of coatings is shown in FIG. 4. It is theoretically impossible to achieve the same level of protection against enzymatic degradation because there must be variations among molecules. Even if all particles were coated in the exactly same ways or the delivery system is identical for all mRNA particles, they must have different relative retention or survival times in tissue. After an injection is completed, all mRNA particles are in different tissue environments. I predict that great variations in retention time or traveling distance can be caused by non-identical tissue environments. All cells and tissue environments experienced by different particles must be different due to differences in structural geometries, local blood flow patterns, plasma compositions, locations relative to blood flow, etc. Thus, the coatings cannot be good for all varying conditions in the person. It is expected that a given coating production specification may work well if the vaccine is administrated in one set of conditions but not work well in another set of conditions. It is theoretically impossible to control mRNA's target delivery even for an imagined person.

A much worst problem is that after a coating specification has been designed for a batch of mRNA vaccine, the coatings cannot be good for all people. The coating or other delivery systems cannot have the magic effects of overcoming all influence factors that must differ from person to person (FIG. 5). I predict that enzymatic activities, blood flow properties and local chemical environments, etc. greatly differ due to differences in age, gender, health condition, daily activities, diets, and current environmental factors. This is the same root reason for failure of population medicine. A delivery method that is based on an abstract person cannot be good for all people. Some mRNA particles may be hydrolyzed prematurely, but others may last too long in blood, thus causing off-target expression. Even though intended target is lymph nodes near the injection site, mRNA may enter liver cells, lung cells, brain cells (through the blood brain barrier), spleen cells, nerve cells, etc, purely by chances. mRNA uptake population in a specific tissue or organ depends on injection site, local hydrodynamic pressure, physiological condition, and vascular micro networks. Some vaccinated persons may experience strong adverse reactions while others may experience mild but delayed adverse reactions. The strong support to this prediction is the wide ranges of side effects reported in the CDC VAER database. If the injection needle happens to insert into a vein, the mRAN particles can instantly reach the heart.

The risk of COVID-19 mRNA are much bigger than other vaccines because of its smaller sizes. The mRNA is just a sub-unit for encoding the spike protein. The SARS-CoV-2 genome is composed of approximately 30,000 nucleotides, which encodes four structural proteins include spike (S) protein, envelope (E) protein, membrane (M) protein, and nucleocapsid (N) protein [58]. Due to the small size, mRNA is much smaller and could more easily penetrate into any types of cells. The whole SARS-Cov-2 virus is much bigger and can enter only a few types of cells. This explains why the number of adverse effects of mRNA vaccines is actually far more than the number of well recognized symptoms of the COVID-19 disease.

Since the start of administrating mRNA vaccines in the U.S. population, recently published articles [20, 52-53] have dropped those technical difficulties issues that were well 
known. None of the well known delivery systems or methods can satisfactorily address all problems revolving around mRNA uptake and off-target expression and accompanied risks to recipients. Those problems are fundamental: the inability to address those problems is same as the inability to cure diseases by using population-based treatments. Population medicine disregards the differences attributable to gender, age, health condition, lifestyle, environment factors, emotional state, etc. Each batch of mRNAs is intended for all people even though they are very different. Uncontrollable systemic distribution and off-target expression must hurt different people in different ways. They may aggregate existing chronic diseases if mRNA enter cells in inflamed tissues and express. In addition, an increased number of immune cells circulate in blood is preferentially caught at the diseased tissue [31].

\section{Potential Reverse Transcription and Insertional Mutation}

Based on literature, the consensus is that reverse transcription cannot happen. No one can guarantee that reversed transcription from RNA to DNA will never happen because such a prediction is based on an unrealistic and imagined model, which leaves out thousands of factors from the equation. No one can rule out special conditions which may be created by other substances or another disease agents such as HIV or other retrovirus. It is known that DNA vaccines carry a potential risk of integration into the host genome, which may result in insertional mutation. mRNA could require more steps to achieve it. Once the vaccine mRNA is delivered to the cytosol, its pharmacology is governed by the same complex cellular mechanisms that regulate the stability and translation of endogenous mRNA. I note that many articles argued that mRNA cannot get into cell nuclei. Those predictions are based on abstract models or very limited data. In the real world, persons may carry different disease pathogens that can produce required enzymes and building materials to produce new disease agents or biological systems which can insert a newly created DNA segments into an existing viral genes, body cell DNA chain, bacteria gene which happen to exist in the body, etc. Outcomes from limited animal studies cannot be extended to billions of humans, who can never be under control or may carry various viruses, bacteria, insects, and synthetic compounds. The perceived transportation barrier to cell nuclei is not an absolute one.

To see how unreliable past predictions can be, I urge readers to consider how the genetically modified organism (GMO) raises cancer risks. There is no direct basis to predict that GMO can raise cancer risks for humans. Researchers could not think about omega 6/3 fatty acids ratio before they conducted genetic modification. When cheap GMO feeds with high omega 6/3 fatty acids ratio are widely available, they replaces grass feeds. It is this farming practice that alters omega 6/3 fatty acids ratio in animal meats. It is even more unpredictable that, when most domestic animals such as pigs, chicken, cows, etc. are feed with GMO feeds, this farming practice slowly alters omega 6/3 fatty acids ratio in the Western diet, which ultimately affects human health [83-85]. No body could foresee how altered genetic compositions in food and feeds will affect cancer risks. Based on repeated failures, I must say that alteration of natural phenomena always pose inherent risks that cannot be predicted reliably due to the overwhelming number of influence factors. Reliable prediction is plausible only if the research model can include all observed and potential influence factors and is sufficiently accurate to characterize each influence factor. There is no possibility for this reductionist science to satisfy both two requirements.

\section{J. Interfere With Vital Cell Functions}


Another problem, which is a big one, is that vaccine-triggered protein synthesis must infringe normal protein synthesis. The two processes compete for same amino acids as building materials, catalyst enzyme, energy, space, etc. The expected mechanisms for interfering normal protein synthesis include:

(1) Compete for ribosomal RNA (rRNA), and transfer RNA (tRNA). The synthesis of mRNA, tRNA, and rRNA is accomplished by an enzyme called RNA polymerase. The presence of spite protein mRNA is expected to have an effect like a product-feedback. Thus, it would inhibit the synthesis of mRNA for normal protein. If vaccine mRNA is self-amplified to generate more mRNA copies, this amplification process interferes with normal mRNA synthesis because they compete for building blocks for mRNA.

(2) Compete for all required enzymes for protein synthesis (e.g., translation) and also compete for the energy which is used to create amino acid chains. For example, spike protein synthesis and normal protein synthesis compete for peptidyl transferase, which is the main enzyme used in translation. The enzyme's activity is to form peptide bonds between adjacent amino acids using tRNAs during translation. The enzyme uses two substrates of which one has the growing peptide chain and the other bears the amino acid that is added to the chain.

(3) Compete for space for protein synthesis. Protein synthesis takes place in cytoplasm. When spike protein synthesis takes place, the synthesis must occupy space and reduces space available for synthesis of structural proteins and catalyst proteins.

(4) Compete for both non-essential and essential amino acids. Amino acids work like building materials for protein. If there are too many spike protein synthesis sites, their availability for normal protein synthesis is reduced. The impact may be on the cells where spite protein is synthesized and found in remote cells. When a large number of cells are involved in spike-protein synthesis, they are predicted to use up amino acids and thus depress amino acids concentrations in blood. It may cause a temporary amino acid shortage.

(5) Altering cell state: whenever a tissue cell has spike protein synthesized, the cell will be marked as a cell for destruction by the immune system.

Predicted impacts include reducing mRNA synthesis for normal proteins, using spaces or sites for synthesis of spike protein, using up amino acids for spike protein synthesis, reducing the amount of structural protein and catalyst proteins for cell normal functions, and marking the cell for T cell attacks. Since mRNA can circulate in blood and can enter into any type of cells, the scope of impacts is widespread: the vaccine affects all vital organs including brain, liver, lungs, kidneys, spleen, all nerves, etc. as long as mRNA vaccines can get into organs or tissue cells. This must be true to near all people under all conditions as discussed in Section $\mathrm{H}$. It is even possible that mRNA triggered protein synthesis may temporarily deplete amino acids and energy, and thus impairs all protein synthesis processes for making vital structural proteins and enzymes.

All "safe" prediction is based on deeply flawed reductionist model which is based on unreasonable, unrealistic and clearly flawed assumptions: the tissue has unlimited building materials, slowing down normal protein synthesis will not hurt the host person, and amplifying mRNA is very limited or can be controlled and will not disrupt normal RNA synthesis. No study has proved each of the assumptions. Each assumption must be wrong, unrealistic and grossly 
inaccurate to the scientists with knowledge and training in basics of chemistry and physics. No long term study has been done to understand their side effects. Even if long-term studies have been done, their findings cannot take into account hundreds to thousands of real variables.

One biggest risk is impairment to protein synthesis in the brain and thus mRNA vaccines are particularly harmful to the brain. Establishing proper neuronal connections during brain development and eliciting appropriate responses to environmental stimuli in the adult, requires precisely regulated protein synthesis. Many brain functional mechanisms target mRNA-binding proteins and ribosomal sub-units to regulate protein synthesis initiation. These mechanisms are especially concentrated at synapses, where they act to transform transient electrical signals into lasting functional modifications that are a basis for learning and memory, and misregulated synaptic protein synthesis contributes to several human cognitive changes including addiction, fragile $X$ syndrome, and autism [111]. The S1 protein of SARS-CoV-2 can crosses the blood-brain barrier in mice [112]. While native mRNA cannot easily cross the brain blood barrier, the lipid coatings may facilitate mRNA to cross the brain blood barrier [113]. In addition, mRNA may even interfere with brain blood barrier because carrier protein such as brain-type glucose transporter is synthesized by using mRNA [114]. Since mRNA must be present in neurons and brain blood barriers, the presence of foreign mRNA must interfere with all normal protein synthesis in blood brain barrier cells. When mRNA gets into the cells in the blood barrier, it may impair the brain blood barrier integrity by impairing carrier protein synthesis or cause the cell to be destroyed by the immune system. When mRNA gets into neurons, it interferes with normal protein synthesis in the neurons and thus leaning and memory. Each time when a cell is converted into a spike protein-containing cell, it becomes destruction target of the immune system. Cytotoxic T-cells may kill spike protein-expressing brain cells and BBB cells. The damage is hard to repair because neurons in the brain rarely regenerate. In addition, by altering the integrity of the brain blood barrier, the vaccine is predicted to alter material compositions in the blood inside the brain. Vaccine recipients have reported lost memory and dramatically reduced intellectual capacities. The massive number of signs reported in CDC database are consistent with what would be expected from disrupted normal protein synthesis.

Vaccination of pregnant woman with mRNA vaccines may impair fetal brain development, resulting in future mRNA BABIES. Another even bigger risk is mRNA vaccine may irreversibly disrupt vital protein synthesis function. This risk may be seen on a person, whose protein synthesis function is nearly a limited factor due to aging, poor health, preexisting cellular damages, chronic diseases, and inhibitory effects of toxic substances. The mRNA cytokine storm can cause increased stress on all vital organs. By disrupting the normal protein synthesis, the vaccination results in depletion of biological resources (e.g., enzymes, proteins, energy and all other required compounds), which are necessary for sustaining life and restoring organ functions and repairing damages. Those two adverse effects put affected organs or parts in a condition that is unable to resolve vaccine-induced inflammation and damages. This risk is underscored by another known fact: a diseased state is nearly always persistent. For example, obesity cannot be easily corrected; immune responses have lasting memory role [44], changed gene expression in lead poisoning is persistent after removal of lead from the body [5], etc. I reasonably suspect that hijacking the cellular machinery from synthesizing life-sustaining proteins to generating spike proteins is bad innovation. It is unclear whether the normal protein synthesis can be fully restored, but my prediction is 
negative. Even if the normal protein synthesis function can be fully restored, the combination of vaccine cytokine storm and diminished resource availability for protein synthesis is dangerous to some recipients. This theory can explain why some recipients feel fatigues and lack of energy for extended times while other recipients feel they have become different persons [such instances could be tabulated]. It is possible that some people could not restore the normal protein synthesis function.

\section{K. Most mRNA Vaccine Acute and Latent Effects Are Concealed By Varying Organ Reserve}

Clinical trials and controlled studies are good at ascertaining strong effects of any drug or treatment, but cannot detect slowly-delivered long-term effects of anything due to a large number of interference factors. Based on observed case outcomes discussed above [4-11] and all removed harmful drugs [12], the chance of failure of clinical trials and controlled study is nearly $100 \%$. I could not find a single case where clinical trials correctly predicted future adverse health effects. The failure is deeply rooted in the reductionist model: all models used in studies are unable to include all potential variables [2-3]. The mRNA vaccines are like a super virus with high penetrating power, they are capable of getting to any types of cells except they cannot transmit from human to human. Their short-term benefits are based on the increased immune system's sensitivity while they have dramatic impacts on the vascular system, the CNS, kidneys, lungs, spleen, liver, etc. Due to their small sizes and high penetration power, they can get into any tissue and are expected to cause a large number of symptoms. I predicted that true adverse impacts on people is $100 \%$.

However, huge vital functional capacities [15-18] (with large surplus functional capacities) in a super majority of people can conceal true adverse effects of the vaccines in the population data. As shown in FIG. 2, if the adverse reactions do not depress their vital functional capacities to nearly disability levels, the recipients most likely feel no symptom. The observed "no harm" on those healthy persons thus dilutes their true adverse effects on a small number of vulnerable people to produce the false impression of "no harmful effect". In addition, as I have shown that vaccines must add burdens to the vascular system and thus increase the chance of death; but due to lack of distinctive symptoms, most vaccine-triggered deaths are routinely improperly attributed to other causes such as COVID-19 infection, other diseases, or natural causes. All deaths caused by disrupted brain functions may be improperly attributed to other causes. If a limited number of mRNA enters the brain or nerve cells, their effects may be not strong enough to impair recipients' feeling and sensation. That does not mean no alteration has taken place or that alterations can be fully reversed. If vaccine recipients have existing diseases, the vaccines may aggravate them. If adverse effects at disease sites are resolved, the vaccines may cure the diseases as an incidental benefit. If vaccine recipients have previously healed diseases, the vaccines may cause the diseases to relapse (based on self reports). Under influences of a large number of factors and variables, vaccine adverse effects must be manifested as different symptoms. I predict that, after making adjustments to correct research model flaws, both efficacy rate and adverse reaction rate are 100\%. However, the long-term adverse effects are not known at both personal levels, population levels, and viral evolution level. At the personal level, vaccines harm the recipients by reducing vital functional capacities while their acute adverse effects may be realized by adding additional burdens onto the vascular system. 


\section{Second Shots and Booster Shots}

In a natural disease course, immunization is acquired after getting a first infection of a particular disease agent. The first infection leaves immunological memory so that when the person is exposed to the same disease agent, the immune response will be much faster and efficient. However, in all natural infection processes, all expected future exposures are always limited to a very limited number of seed pathogens: perhaps one, several, thousands or millions in the worst situation. It can never be in the number like $10^{9}$ to $10^{11}$ from a shot. We also know a similar reason in managing allergic reactions: after a person has become sensitive to a compound, exposure to the compound even at moderate amount must be avoided. Both those two observations tell that after the immune system has been sensitized, exposure to a large number of antigens is a forbidden thing. This rule is set in evolution. The rationale of avoidance of severe sequential exposures can be shown in FIG. 6 . The figure shows that the first vaccine shot will generate a small cytokine storm but administrating the second shot must cause much severer reactions. Each cytokine storm can cause acute organ injury. In addition, the first shot or each additional shot is presumed to have latent adverse impacts on organs and thus diminishes organ's functional reserve. The ability to withstand the vaccine impacts is shown in the green line SM1 and SM2, which is predicted to become smaller and smaller with successive vaccine shots. For those 12 to 39 years old, heart inflammation was 4.4 cases per million first shot but increased to 12.6 cases per million in second shot [28]. Those numbers are not based on cellular damages. Successive vaccinations with the same vaccine would progressively reduce the safety margins. While this is not a big risk for healthy persons who have massive vital functional capacities (particularly biological resources), the vaccine could cause expected damages by erratic mRNA particles. Additional booster shots are predicted to pose much bigger risks due to activated immune system. Due to differences in vital functional capacities, and unpredictable acts of mRNA, the amount of permanently lost organ functional capacities cannot be determined. I predict that keeping being vaccinated successively will end with death as a theoretical limit. This prediction can be easily validated by successively vaccinating any laboratory animals. For people with their vascular functions at near disability levels, booster shots could pose much high risk of death.

I also predict that, if booster shot's cytokine peak and COVID-19-induced peek happen to superimpose, they can dramatically raise blood pressure or burden the kidneys. The total number of mRNA copies delivered in a vaccine shot can be computed. The vaccine cytokine storm is a front-peaked curve while the COVID-19 cytokine storm has a progressively rising curve. The total number and mass of SARS-Cov-2 virions in a real infection can be determined in ballpark [67]. Based on those numbers and observed disease progression course, the viral impact curve and the vaccine impact curve must be very different. The vaccine peak could be much larger than COVID-19 peak, as shown in FIG. 3. The reason is that more than a billion mRNA particles are injected INSTANTLY to produce spike protein in a very short time, while the virus must slowly gain its population against immune system's check. I must say that death in such a situation is caused primarily by the vaccine rather than the COVID-19 infection.

In predicting the adverse effects of mRNA vaccines, I must consider past failures in predicting latent side effects for asbestos, lead paint, DES, GMO, Roundup and removed drugs because their failures are rooted in the same model flaws. In each instance, no or little 
evidence existed for making prediction of future adverse health effects, but final outcomes, which often appeared decades later, are catastrophic to public health. mRNA vaccines have far more bad signs for predicting their bad outcomes. Those signs include well known technical difficulties, poor stability, uncontrollable uptake, off-target expression, interference with normal protein synthesis, and the overwhelming number of reported side reactions. Its central mechanisms are to disrupt or interfere with the vital cell machinery for maintaining life, they are predicted to be more vicious than the virus; and current prediction by other researchers is largely based on abstract model or oversimplified animal models with thousands of real variables being ignored. By using our multiple factors disease causes model and our kinetic analysis, it is absolutely clear that booster shots are not a proper measure for the population.

\section{DISCUSSION}

\section{A. True Risks of mRNA Vaccines}

mRNA vaccines' central injury mechanisms are (1) inflammation caused by spike protein synthesized mainly by erratic mRAN in any suitable cells in any tissue, (2) disrupting normal protein synthesis in the affected cells and tissues, (3) altering the immune system, and (4) interfering with viral evolution. Many additional adverse effects may be derived from any of those combination. Other potential effects of inactive ingredients are not explored but cannot be precluded. mRNA vaccines must cause acute personal injuries if any of the (1) to (3) mechanisms add more burden than what the major organs can bear, as in vulnerable people and people with limited organ functional reserves. The alteration of immune system may be against the bounds set in evolution and may excessively increase the number of immune cells in the body. Those mechanisms also cause latent personal injuries if their impacts are not enough to consume organs' functional reserves, but wear out a small portion of the vital functional reserves by each vaccine injection. Due to the massive surplus functional capacity in health persons, their latent side effects will not felt, and nor detected. However, subtle adverse effects may be done to cells and tissues. The biggest damage may be caused by dramatically raised blood flow resistance, and at the same time disrupted normal protein synthesis for maintaining organ's functions. It is particularly danger for second and additional booster shots because they must generate unreasonable cytokine storms, elevated immune cells count, and more severely disrupted normal protein synthesis. This triple combination must be deadly to a good number of people and their danger can be further aggravated by environmental factors (e.g., temperature) and mistreatment. Since the locations of damages are unpredictable, mRNA vaccines must cause unlimited number of non-distinctive side effects. The big vaccine cytokine storm will become the primary or contributory cause of death in all kinds of scenarios. Within the cytokine striking time window, all deaths should be attributed to the vaccines even if other factors might be contributory factors. It is so even if the person dies from fire, flood or an accident because the vaccine can temporarily depress the person's ability to withstand the physical injury. While the cells' ability to restore normal protein synthesis or normal immune function is unknown, diseased state's persistence in various situations tend to support my suspicion that those changes cannot be restored in a short time, or even in the remaining lives of the recipients. Some potential latent injuries may become 
detectable years to decades later. Vaccine impacts on the CNS seem to be severe because brain tissues could be the sites of erratic mRNA's attacks, and elevated blood pressure must affect the brain as well. Vaccination of pregnant women with mRNA vaccines will pose material risks of creating children with diminished mental capacity or mental diseases (See Sections $\mathrm{C}, \mathrm{J})$.

The fourth mechanism is altering viral evolution, due to reduced vigilance for protection, asymptomatic infected people will have higher chances to develop new virulent variants and pass the developed variants out to others. The severity of this impact cannot be accurately determined without conducting long term study and follow up. I predict that mRNA can dramatically increase total death rate among both vulnerable and healthy people. Due to use of symptom-based approach and distortions by superimposing lifestyle and activity factors, the vaccines appear to reduce COVID-19 deaths but transfer the causes of death for most deaths to other causes such as infections, chronic diseases, heart attacks and stroke, or natural causes. The elevated total deaths attributable to mRAN vaccines can be estimated by a long-term study that focuses on cellular damages rather than symptoms. As a whole, the preliminary data, observations, mechanism-based predictions in light of past similar catastrophic personal injuries force me to reach a conclusion that mRNA vaccines are responsible for increased incidences and deaths.

\section{B. Reasons of Failure to Predict Latent Side Effects}

Past researches have consistently failed to predict latent side/adverse effects for drugs, chemicals, or appliances. The failure can be traced to the reductionist research model's fundamental limitations. Two main problems are the symptom-based side-effect evaluation method and use of abstract disease mechanisms. Cellular damages by drugs and vaccines can take place soon after exposure while symptoms will show up only after they have consumed the massive organ surplus functions. The appearance of symptoms normally has a lag from several years to seven decades. In addition, the slow-delivering effects of harmful drugs are concealed by the interference effects of a massive number of lifestyle factors. Even if future research model uses cellular damages as the evidence of personal injuries, such a model will be very complex. By following the current research model, one could assume that each health problem is controlled by only one or a few factors. Any prediction by using such a simple model must be inaccurate and unreliable. The establishment of multiple factors disease causes model has refuted the abstract disease mechanisms. Most disease mechanisms cannot explain the effects of a large number of lifestyle factors. Studies have revealed a large number of biological and cellular processes that are run inside cells. While the discovered pathways network is very complex, such a network is abstract and oversimplified because it fails to take into account all influencing factors, their interactions, material transport, compartment effects, biological processes competition, phases and timings of biological processes, chemical environment, physical condition, effect of environmental factors, etc. By focusing on one single pathway, one could theoretically tell how a drug might cure a disease. In reality, such an attempt always ends up with failure for two reasons. First, there is no way to predict how a drug might affect all other pathways in the network. It is impossible to predict the precise impacts of the drug on each of all pathways in the network. Second, realistic pathways network is much more complex than abstract pathways. What is far more important is their reaction rates and their relative speeds. Each pathway is influenced by local material concentration, transportation speeds of all involved compounds, and 
interference of all materials surrounding them. It is further affected by emotion and environmental factors. Temperature and emotion stimuli may affect different pathways in different ways. What makes prediction even more difficult is the fact that chronic diseases are often caused by only very small imbalances. I have showed elsewhere only a tiny imbalance (1\% to $0.01 \%)$ in biological process attributes can cause a severe long-term health problem $[2,31]$ while research data can depart from reality by huge margins. The inability to take into account most influence variables implies that realistic mechanisms are magnitudes more complex than the abstract steps. A realistic disease model must be able to take into account all known causal factors, emotional, environmental factors, etc. in sufficient accuracy. Health problem and disease mechanisms cannot be accurately represented by any known methods such as mathematical models, descriptive models and mechanical models. From both medical literature and court reported cases, I could not find one single instance that clinical trials correctly predicted the nature and severity of drug latent side effects. Moreover, even if studies have been done, findings can be still wrong if studies are not focused on specific problems. Even studies have been done correctly, the findings are still inapplicable to specific persons due to great differences between different persons. There is a clear need to explore all limitations of the reductionist research models. Understanding of model limitations will affect how findings from existing mechanism studies are used in clinics.

\section{Explore Generalized Mechanisms for Belated Personal Injuries}

By observing a large number of latent personal injuries, I found four classes of latent personal injuries. The first class is caused by inert substances which can be entrapped in tissues and cells. Representative examples are asbestos, fiberglass, inert films (e.g., perforated polymer film implants), and "forever chemicals" [6, 79-81]. They can cause cancer and other chronic diseases even though no good mechanisms have been established. The second class of personal injuries is caused by altering human biochemical and cellular processes. Representative examples of this class of culprits are stressors [82] and DES [9, 51]. All what they do is altering natural biological process attributes (mainly their relative reaction rates). When the natural biochemical processes are interfered by things such as synthetic drugs and life stress, some processes may run with their attributes falling outside the expected bounds set in evolution, resulting in a range of diseases including cancer. The third class of personal injuries is caused by substances that can disturb cells' biological pathways networks. Potential culprits for this type of injuries include malnutrition and unbalanced nutrition (e.g., the omega 6/3 radio) [83-85]. Damages are realized by slowly altering cell structures, tissue structures and organ structures. The forth class of personal injuries is caused by toxic substances such as drugs, chemicals, and toxic contaminants [86-89]. They directly or indirectly damage cells and tissues in the body by known mechanisms. Time lags between cellular damages to appearance of the earliest detectable symptoms are several years to several decades [97, 109].

mRNA risks can be appreciated by considering the role of stress hormone. Releasing stress hormones in the level and frequency anticipated in the fight and flight in nature is beneficial to health, but persistently elevated stress hormones in blood can cause a range of health problems [82]. This fact shows that the line between harmful and beneficial health effects is set in evolution. The evolution's role in defining bounds of biological processes is also reflected in DES injury case. DES works to alter natural hormonal processes in the following manners: "Estrogens diffuse into their target cells and interact with a protein 
receptor, the estrogen receptor. Target cells include the female reproductive tract, the mammary gland, the hypothalamus, and the pituitary. The effect of Estrogen binding their receptors causes downstream increases the hepatic synthesis of sex hormone binding globulin (SHBG), thyroid-binding globulin (TBG), and other serum proteins and suppress follicle-stimulating hormone ( $\mathrm{FSH}$ ) from the anterior pituitary. The combination of an estrogen with a progestin suppresses the hypothalamic-pituitary system, decreasing the secretion of gonadotropin-releasing hormone ( $\mathrm{GnRH})$ " [50]. Every step affected is a natural process in the female. It is absolutely impossible to predict those mechanisms could lead to a large number of cancer and severe diseases [51]. This example shows that predictions based on abstract biological mechanisms are unreliable.

The toxicity of glyphosate was well known and well documented before 2004 [89]. A 2014 study of glyphosate found its neurotoxicity, stating “...these results demonstrated that Roundup ${ }^{\circledR}$ might lead to excessive extracellular glutamate levels and consequently to glutamate excitotoxicity and oxidative stress in rat hippocampus [90]." Hippocampus is a complex brain structure responsible for learning and memory. This plastic and vulnerable structure can be easily damaged by a variety of stimuli and is involved in a variety of neurological and psychiatric disorders. Such latent effects cannot be predicted by populationbased studies using symptoms-based evaluation methods. By considering how hormones and DES affect health, we could reliably predict the effects of chronic exposure to Roundup. One could predict that glyphosate would impair the immune system, speed up cancer development, severely injure fetus and children. After Roundup was found defective, researches have found cytotoxic and genotoxic effects [91], and recent studies indeed conformed that it impairs human immune system [91], causes autism-like behaviors in male juvenile offspring after maternal glyphosate exposure [92], and increases the risks for getting many types of cancer [93-99]. Discovering acute toxicities seems reliable after glyphosate has become the focus of research interest. By carefully considering the roles of the brain, one would predict glyphosate can cause other health problems [100-103]. In addition, one should predict potential ecological impacts [104].

Approach used by regulatory authorities such as FDA and EPA is clearly unworkable. The failure to predict DES adverse effects were strikingly similar to the failure in predicting Roundup's adverse effects. Considering flaws in the research model, a differential rule should be used: negative animal study finding should be given no weight but a positive finding of harmful effects may not be dismissed. The EPA considers glyphosate as "not likely to be carcinogenic to humans." EPA asserted that there was no convincing evidence that "glyphosate induces mutations in vivo via the oral route [106]." The approach is clearly obsolete, with two problems. It is now clear that genetic mutation is not a required condition for developing cancer and indeed mutation is often responsive to developed cancer [79]. Even for cancer that is accompanied with genetic mutation, positive evidence of mutation in animals most probably appear in much later time. By using this approach, regulatory agencies routinely miss opportunities for catching up the earliest signs of personal injuries for defective products. A harmful product will be found only after a sufficient number of exposed people have developed symptoms which must comprise sufficient cellular damages to consume all organs' redundant functions so that the symptoms can "jump out" from the background data against all interference factors. By this time, a big human tragedy cannot be prevented because all exposed people will continue to develop their symptoms in years and decades to 
come. Previously undetectable cellular damages caused by defective drugs will become detectable symptoms as a result of continuous exposure or diminished organs' functions attributable to aging, infections, chronic diseases, or life stresses. Massive signs about the harmful effects of glyphosate were known long before [108], but never get attention from regulatory agencies. Due to the flaws in the research model, more than 800 studies done in more than 40 years could not detect glyphosate risks. This approach is responsible for the observed repeated catastrophes, each of which torments people and society for decades to a century, with irreparable damages to environment and ecosystem.

The mRNA vaccines work like the substances that can cause the second class of personal injuries because they can alter natural biological and cellular processes. First, such a vaccine hijacks the life-sustaining protein synthesis machinery to generate spike protein. While the idea is highly creative but meddles both the life-sustaining machinery and the immune system. Second, due to the inability to control target sites and expression degrees, the mRNA vaccines can reach any cells in any organs and parts to cause inflammation. The undesirable activities infringe natural biochemical and cellular processes. Third, as far as the second and booster shots are concerned, the mRNA vaccines generate very large cytokine storms that are not the kind that would be encountered in nature. When second and booster shots are administrated in cold seasons with COVID-19 outbreaks and other viral infections, the vaccines are predicted to add extra burdens on the vascular systems of recipients.

When a vaccine is used on a large population, the vaccine must be absolutely safe, this safety requirement cannot be met by relying on flawed findings from deeply flawed researches. A vaccine must be perfect in all aspects, and must not infringe any of the more than 20,000 genes-encoded proteins, and must not add unreasonable burden to vital organs. Refuting vaccine validity requires a showing of only one problem. I have shown so numerous known and potential problems. The problem has been very severe: some vaccine recipients reported that they had become different persons or substantially lost their intellectual capacities. They were sick for days and weeks, and yet such experiences were not part of reported vaccine adverse reaction data. Based on all evidence, I thus conclude that chances of finding vaccine defectiveness is very high or nearly unity, and the chance of seeing them as harmless products is nearly zero. I urge everyone reading this article to think deeply and do not trade your health and life for $\$ 100$ or a job.

\section{Dissemination of Science Is Influenced by Business}

Vaccine benefits and risks are questions of science. Thus, vaccine merit is determined by natural law. The approach to discovering scientific truth is different from what is used in legal processes and business. The interference of medicine by legal wills, media, and business practices are responsible for inability to improve medicine. Leading media have failed to report minority's voices against those clearly dangerous vaccines. Few reports have directed to side effects [70-74] and controversial lawsuit to enjoin the vaccines [74]. When medical science can be manipulated by personal belief and business practices, medicine does not need to seek best treatments or real cures. Most people do not know that reducing a few percents of vital functional capacities can result in a loss of many years of lifespan. This practice causes societies to rely on flawed science to their detriments. The worst danger is when all media are biased to reporting only what appears to be right or what favors their revenue. It is especially dangerous when media uses its monopolistic power and concerted 
efforts to disseminate only one-side stories, but suppress conflicting stories. Such practice has the same affects of defeating informed consent in the largest scale, and causing the whole population to accept dangerous vaccines. Such practices hurt not only the whole population, but the decision-makers' own health and their own family health. It is equally improper when employers provide incentives to encourage their employees to accept the vaccines [76-77]. Inducement by giving a small amount of money or coercion by terminating employment is equally unjust. If the vaccines are good, companies do not need to offer money as incentive. If vaccines are bad, paying $\$ 100$ to ruin their health or cause their death is simply wrong.

\section{E. Neglected Pandemic Measures}

There is no good antiviral drug for the COVID-19 disease [78]. The COVID-19 is not a severe disease. Many studies have fully mapped out those at risk. It is agreed that more than $80 \%$ infected people may show only sign of mild disease or no disease. The death rate is about $2-4 \%$, but deaths happen only among a small number of vulnerable persons [60-61] or persons who have been exposed to a large amount of viral copies [38]. Those who are vulnerable to the disease can be identified by looking at the risk factors [61], and take additional measures. Transferring incidence/death risks from a small number of vulnerable persons to the whole population is another flaw of population-based approach. This flaw is responsible for disrupting people life and shutting down economy and travel.

The reported incidence/death data clearly show that lifestyle and environment factors are responsible for at least 100 folds differences. On March 13, 2021, the death rate of $1644 /$ mil for the U.S. is much higher than the death rates for many other nations, which are 0.4-120/mil. Even Japan, which has a high old people population, high population density, with a culture of high work stress, has a death rate of about $67 /$ mil for the entire period. While many factors affect incidence and death rates, I found that lifestyles and cultural factors caused more than ten (10) times differences. The amendable nature of COVID-19 is reflected in many well known facts. I observed that some people get cold and flu routinely, some get them at lower frequencies; and some seldom get them. Even within a family, some members get cold and flu at very low frequencies while other members get them frequently even though they are exposed to the same viruses. The observation also implies that one can avoid severe infections and death by using life skills and proper mitigating remedies. The temperature's effect was reflected in the incidence patterns for each of most nations' incidence data [62] before vaccines were used. It is indeed found that temperature is a super strong influence factor [62-66]. Based on seasonal patterns, temperature is estimated to be responsible for at least 10 times of differences in disease incidence and death rates in any given short time window. Thus, differences in both lifestyle factors and environmental factors (e.g., temperature) are responsible for more than 100 times difference in incidence rate and death rate. Those factors would be used to reduce the risk of infection and death to a very low level.

In contrast, reported vaccine benefits $[48,116]$ are inaccurate because the studies failed to take into account the effects of temperature, a super strong factor. This distorting effect cannot be corrected by use of control or comparative study. One reason is that there is no real control and another reason is that incidence/death rates vanish or change with increased temperature by different slopes (in other words, all key assumptions and presumptions used in clinical trials fail, and in addition most model assumptions in the agentbased model are unrealistic). So called-effectiveness like 95\% does not exist because this 
number could be altered easily by manipulating any of a large number of environmental, emotional, lifestyle, preventive factors, etc. The short Pfizer trial started from October 6, 2020 lasing 60 days missed the adverse effects of cold temperature. From Spring to summer in 2021, incidence rate went down dramatically mainly due to nature's help but not vaccines. The perceived low incidence in the first half year cannot be attributed to mRNA vaccines. True incidence rate and death rate in the coming winter will not get nature's help. If I adjust the vaccine's benefits against conflicting effects of temperature, the true short-term benefits of the vaccines are much lower than reported face values. The outcomes of pandemic will depend on how many cold peaks or cold storms that will strike the U.S. in the coming winter. Exposure to very low temperature can cripple the immune systems in affected individuals and vaccine benefits must decline with the crippling of the immune systems.

Since vaccines work through the immune system, a rational strategy is to use measures to boost human immune systems. Failure to take any of many measures will diminish the apparent benefits of vaccines. Societies have not used overwhelming factors that can improve human immune systems. Those factors include body temperature management, selection foods, environment factors, etc. [37-38, 49, 68-69, 82-85, 107]. A person's chance to survive the COVID-19 disease depends on his vascular functional capacity which can be improved by healthy diets [107]. Even other microorganisms can affect the immune system [68-69].

\section{F. Misuse of Pandemic Measures}

I found that a good number of infections have been caused by misused pandemic measures. From TV news, on-line stories and personal observations, I found that this 6 feet social distancing rule is frequently misused, resulting in more new infections and deaths. By enforcing the 6 feet distance, stories or building owners must limit the number of people. They need extra people to enforce the rule by reducing cashiers for checking out. So, most stories close all side doors, back-doors in order to track the number of people in stories. Wrong measures include using inefficient check-out methods, forcing customers to stand in lineups in rain, cold wind, and snow, using fewer cashiers, etc. Those measures dramatically increase check-out time. I even saw that people stood in chilly weather with only little clothing or just $T$ shirts. What those measures have achieved are dramatically increased exposure time, raised viral concentration inside store buildings, and crippled customers' immune systems. Air quality, exposure time, and body health condition determine whether the virus can infect and how severe the disease will be, but 6-feet or the number of people are only speculative parameters that may work in limited situations but not in most situations. Both air quality and exposure time have proportional effects, but personal distance does not. What they should do is improving building ventilation, asking customers to move fast, speeding up check out process, protecting customer health, etc. If a building has too many occupants, a right approach is asking customers to come back later.

\section{G. Question the Vaccination Strategy}

Using mRNA vaccines as primary COVID-19 pandemic measures is a poor strategy. RNA virus mutates rapidly to evade immune responses [34-36]. More than 4000 variants were documented within a year. The total viral samples submitted for U.S. sequence in the international GISAID repository is 140,000 . It is clear that speed of the virus to generate variants is much faster than vaccine development speed. All one can hope that all new 
variants are within the protection scope of developed vaccines. A successful pandemic strategy cannot depend on luck or acts of viral mutations. The consistent failure of past predictions of drug side effects is underscored by the outcome of Roundup (glyphosate) litigation. The finding of Roundup defectiveness implies that societies need to consider all risk indicators in light of the flaws in research models.

I urge governments in all nations to conduct expanded risk analysis before compelling people to use the dangerous vaccines on the population. In making such an analysis, population-based findings cannot be used to preclude alternative pandemic measures and cannot be used to predict the vaccine performance directly. A reliable prediction must go beyond "medically recognized" risks, consider non-published articles, and must not be confined to common belief. The prediction must made without predetermined biases of any kind. A better and reliable prediction must be based on a combination of methods comprising mechanism studies, personal experiences, animal studies, observed symptoms, personal data from clinical trial studies (but not the conclusion), common sense, and wisdom. In predicting latent effects, one must learn two kinds of standards: a positive adverse effect in animal studies may be extended to humans as substantial evidence, but a negative finding cannot. If governments must use mRNA vaccines, they must let recipients know all risk indicators, known adverse reactions, expected risks, and unknown and unpredictable risks. No-harm findings from short-term clinical trials must be presented with factual evidence to show repeated and consistent failures of such evidence in predicting latent personal injuries and to show the flaws of using symptoms to find injuries. If those facts are not told, people cannot make informed consent to vaccinations.

\section{CHANGE HISTORY}

The draft was written on March 17, 2021. All key risk predictions are first presented in the original version. It was revised October 24, 2021 and October 31, 2021. Abstract was presented in Pulsus Annual Congress on Vaccines and Immunization October 11-12, 2021.

\section{FUNDING STATEMENT}

This research is not supported by any source of private or public funds.

\section{CONFLICTS OF INTEREST}

None. The author writes books on this subject after all hypotheses were disclosed on March 17, 2021. The book(s) expand or elaborate what has been proposed in the earliest posed article. As such, there is no incentive to make one finding over another. In addition, all cited data come from published articles by other researchers, the author cannot influence any 
aspects of those data. The analytic method is a matter for public scrutiny.

\section{REFERENCES}

1. CDC, Vaccine Adverse Event Reporting System (VAERS). March 14, 2021 https:// www.cdc.gov/vaccinesafety/ensuringsafety/monitoring/vaers/index.html

2. Wu J, Zha P. Randomized Clinical Trial Is Biased and Invalid In Studying Chronic Diseases, Compared with Multiple Factors Optimization Trial. Preprints 2019, 2019110245. Accessed from https://www.preprints.org/manuscript/201911.0245/v1. DOI: http://dx.doi.org/ $10.2139 /$ ssrn.3480523

3. Wu J, Zha P. Clinical Trials and Reductionist Approach Preclude Cures for Chronic Diseases Due to Flawed Presumptions. Preprints 2020, 2020090572 (doi: 10.20944/preprints202009.0572.v1). Accessed from https://www.preprints.org/manuscript/202009.0572/v1 Lead_paint.

4. Lead paint, Wikipedia. Retrieved March 6, 2021, from https://en.wikipedia.org/wiki/

5. Gillis BS, Arbieva Z, Gavin IM. Analysis of lead toxicity in human cells. BMC Genomics. 2012; 13: 344. doi: 10.1186/1471-2164-13-344 bestos

6. Asbestos. Wikipedia. Retrieved March 6, 2021, from https://en.wikipedia.org/wiki/ As-

7. DDT. Wikipedia. Retrieved March 6, 2021, from https://en.wikipedia.org/wiki/DDT

8. Orange Agent. Wikipedia. Retrieved March 6, 2021, from https://en.wikipedia.org/ wiki/Agent_Orange

9. Diethylstilbestrol. Wikipedia. Retrieved March 6, 2021, from https:// en.wikipedia.org/wiki/Diethylstilbestrol

10. Roundup. Wikipedia. Retrieved March 6, 2021, from https://en.wikipedia.org/wiki/ Roundup_(herbicide)

11. Bailey R. (February 21, 2019) A New Study About Roundup and Cancer Doesn't Say What You Probably Think It Does. Epidemiology. Retrieved from https://reason.com/ 2019/02/21/roundup-ready-cancer/

12. List of withdrawn drugs. Wikipedia. Retrieved March 6, 2021, from https:// en.wikipedia.org/wiki/List_of_withdrawn_drugs

13. Zhang L, Rana L, Shaffer RM, et al. Exposure to glyphosate-based herbicides and risk for non-Hodgkin lymphoma: A meta-analysis and supporting evidence. Mutation Research/Reviews in Mutation Research. July-September 2019:781:186-206.

14. Andreotti G, Koutros S, Hofmann JN. Glyphosate Use and Cancer Incidence in the Agricultural Health Study. JNCl: Journal of the National Cancer Institute. May 2018;110(5):509-516, https://doi.org/10.1093/jnci/djx233

15. Bortz WMT, Bortz WM 2nd. How fast do we age? Exercise performance over time as a biomarker. J Gerontol A Biol Sci Med Sci. 1996;51:M223-5. 
16. Goldspink DF. Ageing and activity: Their effects on the functional reserve capacities of the heart and vascular smooth and skeletal muscles. Ergonomics. 2005;48:1334-51.

17. Sehl ME, Yates FE. Kinetics of human aging: I. Rates of senescence between ages 30 and 70 years in healthy people. J Gerontol A Biol Sci Med Sci. 2001; 56:B198-208.

18. Wu J, Zha P. A Multi-Factor Model for Estimating Relative Lifespans and Extending Health Spans (December 11, 2019). Available at SSRN: https://ssrn.com/abstract=3502432

19. Schlake T, Thess A, Fotin-Mleczek $M$, et al. Developing mRNA-vaccine technologies. RNA Biology. November 2012;9:11,1319-1330. doi: 10.4161/rna.22269

20. Buschmann MD, Carrasco MJ, Alishetty $S$, et al. Nanomaterial Delivery Systems for mRNA Vaccines. Vaccines 2021,9(1),65; https://doi.org/10.3390/vaccines9010065

21. Pardi N, Hogan MJ, Porter FW, et al. mRNA vaccines - a new era in vaccinology. Nature Reviews Drug Discovery. April 2018;17:261-279.

22. Garde D (10 January 2017). Lavishly funded Moderna hits safety problems in bold bid to revolutionize medicine. Statnews. https://www.statnews.com/2017/01/10/moderna-trouble-mrna/). Stat. Archived https://web.archive.org/web/20201116154151/https://www.statnews.com/2017/01/10/moderna-trouble-mrna/ from the original on 16 November 2020. Retrieved 19 March 2021.

23. Garade D (13 September 2016). Ego, ambition, and turmoil: Inside one of biotech's most secretive startups. Stat. https://www.statnews.com/2016/09/13/moderna-therapeuticsbiotech-mrna/. Stat. Archived https://web.archive.org/web/20201116154313/https://www.statnews.com/2016/09/13/moderna-therapeutics-biotech-mrna/ from the original on 16 November 2020. Retrieved 18 Much 2021.

24. Geschwind DH. Genetics of Autism Spectrum Disorders. Trends Cogn Sci. 2011 September;15(9):409-416. doi:10.1016/j.tics.2011.07.003

25. Baio J, Wiggins L, Christensen DL, et al. Prevalence of Autism Spectrum Disorder Among Children Aged 8 Years - Autism and Developmental Disabilities Monitoring Network, 11 Sites, United States, 2014. CDC Morbidity and Mortality Weekly Report (MMWR). Surveillance Summaries April 27, 2018:67(6);1-23.

26. Ozonoff A, Nanishi E, and Levya O. Bell's palsy and SARS-CoV-2 vaccines. Lancet Infect Dis. April 2021;21(4):450-452. doi: 10.1016/S1473-3099(21)00076-1

27. Mordechai S. (Feb 18, 2021) Vaccination in Israel: Challenging mortality figures? Analysis by infectious disease specialist claims mismatch between data published by authorities and reality on the ground. Retrieved from https://www.israelnationalnews.com/News/ News.aspx/297051

28. Soucheray S. Experts: mRNA COVID-19 vaccines likely tied to heart inflammation. News Reporter CIDRAP News. Retrieved from https://www.cidrap.umn.edu/newsperspective/2021/06/experts-mrna-covid-19-vaccines-likely-tied-heart-inflammation

29. Wu J, Zha P. The Central Nervous System's Adaptive Changes Make Chronic Diseases Incurable. Preprints 2019, 2019110287. DOI: http://dx.doi.org/10.2139/ssrn.3480562

30. Amerio A, Gálvez JF, Odone A, et al. Carcinogenicity of psychotropic drugs: A sys- 
tematic review of US Food and Drug Administration-required preclinical in vivo studies. Australian \& New Zealand Journal of Psychiatry. 2015;49(8) 686-696.

31. Wu J, Zha P. Lung Damage Mechanisms For COVID-19 and Other Lung Infections and Driving Force in Leukecyte Recruitment and Migration. Preprints 2020, 2020090209. Accessed from https://www.preprints.org/manuscript/202009.0209/v1. http://dx.doi.org/10.2139/ ssrn.3689090

32. Boots M. The Need for Evolutionarily Rational Disease Interventions: Vaccination Can Select for Higher Virulence. PLoS Biol 2015;13(8):e1002236. doi:10.1371/ journal.pbio.1002236

33. Read AF, Baigent SJ, Powers C, et al. Imperfect Vaccination Can Enhance the Transmission of Highly Virulent Pathogens. PLoS Biol 2015;13(7): e1002198.doi:10.1371/journal.pbio.1002198

34. Domingo E, Holland JJ. RNA Virus Mutations and Fitness for Survival. Annual Review of Microbiology. 1997;51:151-78.

35. Maxmen A. (23 April 2021) One million coronavirus sequences: popular genome site hits mega milestone: GISAID's impressive effort to understand the spread of COVID-19 has seen scientists upload sequences from most nations on Earth. Nature News. Retrieved from https://www.nature.com/articles/d41586-021-01069-w

36. Harvey WT, Carabelli AM, Jackson B, et al. SARS-CoV-2 variants, spike mutations and immune escape. Nature Review Microbiology. July 2021;19: 409-427.

37. Wu, J, Zha P. Mask Is a Double-edged Sword in the Fight Against COVID-19 Pandemic (March 28, 2020). SSRN. Retrieved from https://ssrn.com/abstract=3563851 or http:// dx.doi.org/10.2139/ssrn.3563851

38. Wu, J, Zha P. Proactive Body Temperature Management Protocol and Lifestyle Interventions as Predictable Cures for COVID-19 Disease: Curative Protocols Discovered from a Century of Medical Discoveries. Retrieved from https://osf.io/pcfna, DOI: 10.31219/osf.io/ pcfna 402-412.

39. Sanjuán R. Collective infectious units in viruses. Trends Microbiol. 2017 May; 25(5):

40. Shirogane $Y$, Watanabe S, Yanagi Y. Cooperation between different variants: $A$ unique potential for virus evolution. Virus Res. 2019 Apr 15;264:68-73.

41. Leeks A, Segredo-Otero EA, Sanjuán R, West SA. Beneficial coinfection can promote within-host viral diversity. Virus Evol. 2018;4(2):vey028. DOI: 10.1093/ve/vey028

42. Vignuzzi M, Stone JK, Arnold JJ, et al. Quasispecies Diversity Determines Pathogenesis Through Cooperative Interactions in a Viral Population. Nature. 2006;439(7074):3448.

43. Zaman SB, Hussain MA, Nye R. A Review on Antibiotic Resistance: Alarm Bells are Ringing. Cureus. 2017 Jun;9(6): e1403. 
44. Föhse FK, Geckin B, Overheul GJ, et al. The BNT162b2 mRNA vaccine against SARS-CoV-2 reprograms both adaptive and innate immune responses. doi: https://doi.org/ 10.1101/2021.05.03.21256520

45. CDC. Vaccine Effectiveness: How Well Do the Flu Vaccines Work? Questions \& Answers. Retrieved from https://www.cdc.gov/flu/vaccines-work/vaccineeffect.htm

46. Krammer, $F$. The human antibody response to influenza $A$ virus infection and vaccination. Nat Rev Immunol. 2019;19:383-397. DOI: 10.1038/s41577-019-0143-6

47. Bardage C, Persson I, Ortqvist A. Neurological and autoimmune disorders after vaccination against pandemic influenza $A(H 1 N 1)$ with a monovalent adjuvanted vaccine: population based cohort study in Stockholm, Sweden. BMJ. 2011 Oct 12;343:d5956. doi: 10.1136/bmj.d5956.

48. Moghadas SM, Vilches TN, Zhang K, et al. The impact of vaccination on COVID-19 outbreaks in the United States. Clin Infect Dis. 2021 Jan 30: ciab079. doi:10.1093/cid/ciab079

49. Pedersen AF, Zachariae R, Bovbjerg DH. Psychological stress and antibody response to influenza vaccination: a meta-analysis. Brain Behav Immun. 2009 May;23(4):42733.

50. Diethylstilbestrol. Drugbank. Retrieved from https://go.drugbank.com/drugs/ DB00255

51. Diethylstilbestrol (DES) and Cancer. Wikipedia. Retrieved from https://www.cancer.gov/about-cancer/causes-prevention/risk/hormones/des-fact-sheet\#what-is-des

52. Dolgin E. The Tangled History of mRNA Vaccines. Hundreds of scientists had worked on mRNA vaccines for decades before the coronavirus pandemic brought a breakthrough. Nature. 16 September 2021; 597:318:324.

53. Liang $Y$, Huang $L$ and Liu T. Development and Delivery Systems of mRNA Vaccines. Front. Bioeng. Biotechnol. 2021;9:718753. doi: 10.3389/fbioe.2021.718753

54. Wadhwa A, Aljabbari A, Lokras A, et al. Opportunities and Challenges in the Delivery of mRNA-Based Vaccines. Pharmaceutics 2020;12,102; doi:10.3390/pharmaceutics12020102

55. Diken M, Kreiter S, Selmi A, et al. Selective uptake of naked vaccine RNA by dendritic cells is driven by macropinocytosis and abrogated upon DC maturation. Gene Ther. 2011;18:702-708.

56. Selmi A, Vascotto F, Kautz-Neu K, et al. Uptake of synthetic naked RNA by skinresident dendritic cells via macropinocytosis allows antigen expression and induction of T-cell responses in mice. Cancer Immunol. Immunother. 2016;65, 1075-1083 .

57. Lorenz, C. et al. Protein expression from exogenous mRNA: uptake by receptormediated endocytosis and trafficking via the lysosomal pathway. RNA Biol. 2011;8:627-636 .

58. Lu R, Zhao X, Li J. et al., Genomic characterisation and epidemiology of 2019 novel coronavirus: implications for virus origins and receptor binding. Lancet (London, England) 2020;395:565-574. 
59. Worldometers.info. Incidences and death data for various nations. See both incidences and death pattern for most nations. Accessed from https://www.worldometers.info/ coronavirus/

60. CDC, Severe Outcomes Among Patients with Coronavirus Disease 2019 (COVID19) - United States, February 12-March 16, 2020. The report was posted online on March 18, 2020 as an MMWR Early Release. Weekly/March 26, 2020/69(12);343-346.

61. Verity R, Okell LC, Dorigatti I, et al. Estimates of the severity of coronavirus disease 2019: a model-based analysis. Lancet Infect Dis 2020. Published Online March 30, 2020. Available from https://doi.org/10.1016/S1473-3099(20)30243-7

62. Incidences and death data. worldometers database. See the seasonal treads of incidences and death rates for any of most nations by searching https:// www.worldometers.info/coronavirus/

63. Lowen AC, Steel J. Roles of Humidity and Temperature in Shaping Influenza Seasonality. Journal of Virology. July 2014; 88:14,7692-7695.

64. Evans SS, Repasky EA, Fisher DT. Fever and the thermal regulation of immunity: the immune system feels the heat. Nat Rev Immunol. 2015 June; 15(6): 335-349. doi:10.1038/nri3843.

65. Tzampoglou P, Loukidis D. Investigation of the Importance of Climatic Factors in COVID-19 Worldwide Intensity. Int. J. Environ. Res. Public Health. 2020; 17, 7730.

66. Barcroft $\mathrm{H}$, Edholm OG. The Effect of Temperature on Blood Flow And Deep Temperature In The Human Forearm. J. Physiol. 1943;002:5-20.

67. Sendera R, Bar-Ona YM, Gleizera $S$, et al. The total number and mass of SARSCoV-2 virions. PNAS 2021;118(25):1-9 e2024815118 https://doi.org/10.1073/ pnas. 2024815118

68. Zheng D, Liwinski T, Elinav E. Interaction between microbiota and immunity in health and disease. Cell Research. 2020;30:492-506. https://doi.org/10.1038/s41422-0200332-7

69. Galán JE. Bacterial toxins and the immune system: show me the in vivo targets. J Exp Med. 2005 Feb 7; 201(3): 321-323.

70. Mangiaracina E. (Aug 18, 2021) Lab founder shows damage COVID jab's spike protein inflicts on vital organs. Retrieved from https://www.lifesitenews.com/news/lab-foundershows-damage-covid-jabs-spike-protein-inflicts-on-vital-organs/

71. Aripaka P. (August 11, 2021) EU looking into new possible side-effects of mRNA COVID-19 shots. Accessed from https://www.reuters.com/business/healthcare-pharmaceuticals/eu-drugs-regulator-looking-new-possible-side-effects-mrna-vaccines-2021-08-11/ (mentioning rare heart inflammation)

72. Chapin-Bardales J, Gee J, Myers T. Reactogenicity Following Receipt of mRNABased COVID-19 Vaccines. JAMA. 2021;325(21):2201-2202. doi:10.1001/jama.2021.5374

73. Blumenthal KG, Robinson LB, Camargo Jr CA, et al. Acute Allergic Reactions to 
mRNA COVID-19 Vaccines. JAMA. March 8, 2021;325(15):1562-1565. doi:10.1001/ jama.2021.3976

74. Dreier S. (May 9, 2021) 1,000 Lawyers and 10,000 Doctors Have Filed a Lawsuit for Violations of the Nuremberg Code Covid-1984 Health. Retrieved from https://sorendreier.com/1000-lawyers-and-10000-doctors-have-filed-a-lawsuit-for-violations-of-the-nurembergcodel

75. Delaney P. (Wed Apr 7, 2021) Lifesite News. EXCLUSIVE - Former Pfizer VP: Your government is lying to you in a way that could lead to your death. Retrieved from https:// www.lifesitenews.com/news/exclusive-former-pfizer-vp-your-government-is-lying-to-you-in-away-that-could-lead-to-your-death/

76. Company Release (Feb 5, 2021) Cincinnati, PR Newswire -- the kroger co. (NYSE: KR) Retrieved from http://ir.kroger.com/CorporateProfile/press-releases/press-release/2021/ Kroger-Announces-New-Vaccine-Payment-for-All-Associates/default.aspx (Family of Companies today announced that it will provide a one-time payment of $\$ 100$ to all associates who receive the full manufacturer-recommended doses of the COVID-19 vaccine.)

77. Hubbard K. (May 7, 2021) Want Free Beer or a Chance at $\$ 1$ Million? Get Your COVID-19 Vaccine: Cities, states and businesses are providing perks to individuals who have received their coronavirus vaccines. Retrieved from https://www.usnews.com/news/beststates/articles/2021-05-07/states-cities-and-companies-offer-incentives-to-get-covid-19-vaccine

78. Hongchao P, Richard P, et al. WHO Solidarity trial consortium. Repurposed antiviral drugs for COVID-19 -interim WHO SOLIDARITY trial results. MeddRxiv Preprint. doi: https:// doi.org/10.1101/2020.10.15.20209817 (These Remdesivir, Hydroxychloroquine, Lopinavir and Interferon regimens appeared to have little or no effect on hospitalized COVID-19, as indicated by overall mortality, initiation of ventilation and duration of hospital stay.)

79. Baker SG. The detached pericyte hypothesis: A novel explanation for many puzzling aspects of tumorigenesis. Organisms. Journal of Biological Sciences. 2018;2(1):25-41. DOI: 10.13133/2532-5876_3.10.

80. Beans C. News Feature: How "forever chemicals" might impair the immune system. PNAS April 13, 2021;118 (15) e2105018118; https://doi.org/10.1073/pnas.2105018118

81. Albert Einstein College of Medicine. (N.D.). Environmental Health \& Safety - Fiberglass. Retrieved from https://einsteinmed.org/administration/environmental-health-safety/industrial-hygiene/fiberglass.aspx

82. Segerstrom SC, Miller GE. Psychological Stress and the Human Immune System: A Meta-Analytic Study of 30 Years of Inquiry. Psychol Bull. 2004 July;130(4):601-630.

83. Mariamenatu AH, Abdu EM. Overconsumption of Omega- 6 Polyunsaturated Fatty Acids (PUFAs) versus Deficiency of Omega-3 PUFAs in Modern-Day Diets: The Disturbing Factor for Their "Balanced Antagonistic Metabolic Functions" in the Human Body. Volume 2021 Article ID 8848161 https://doi.org/10.1155/2021/8848161

84. Simopoulos AP. The omega-6/omega-3 fatty acid ratio: health implications. OCL 
2010;17(5):267-275.

85. Simopoulos AP. An Increase in the Omega-6/Omega-3 Fatty Acid Ratio Increases the Risk for Obesity. Nutrients. 2016 Mar;8(3):128.

86. Kim HS, Kim YJ, Seo YR. An Overview of Carcinogenic Heavy Metal: Molecular Toxicity Mechanism and Prevention. J Cancer Prev 2015;20:232-240 (Heavy metals induce oxidative stress, DNA damage, and cell death processes, which must proceed long before cancer is developed.)

87. Jaishankar M, Tseten T, Anbalagan N, et al. Toxicity, mechanism and health effects of some heavy metals. Interdiscip Toxicol. 2014;7(2): 60-72. doi: 10.2478/intox-2014-0009

88. Brandt-Rauf PW, Li Y, Long C, et al. Plastics and carcinogenesis: The example of vinyl chloride. J Carcinog. 2012;11:5. doi:10.4103/1477-3163.93700

89. Bradberry SM, Proudfoot AT, Vale JA. Glyphosate poisoning. Toxicol Rev 2004;23(3):159-67. doi: 10.2165/00139709-200423030-00003

90. Cattani D, Oliveira Cavalli V, Heinz Rieg CE. Mechanisms underlying the neurotoxicity induced by glyphosate-based herbicide in immature rat hippocampus: Involvement of glutamate excitotoxicity. Toxicology 2014;320:34-45.

91. Peillex C, Pelletier M. The impact and toxicity of glyphosate and glyphosate-based herbicides on health and immunity. Journal of Immunotoxicology. 2020;17(1):163-174.

92. $\mathrm{Pu}$ Y, Ma L, Shan J, et. al. Autism-like Behaviors in Male Juvenile Offspring after Maternal Glyphosate Exposure. 2021 Aug 31;19(3):554-558. doi: 10.9758/cpn.2021.19.3.554.

93. Mills PJ, Kania-Korwel I, Fagan J, et al. Excretion of the Herbicide Glyphosate in Older Adults Between 1993 and 2016. JAMA. 2017;318(16):1610-1611. doi:10.1001/ jama.2017.11726

94. Thongprakaisang S, Thiantanawat A, Rangkadilok N, et al. Glyphosate induces human breast cancer cells growth via estrogen receptors. Food Chem Toxicol. 2013;59:129-36. doi:10.1016/j.fct.2013.05.057

95. Portier CJ. A comprehensive analysis of the animal carcinogenicity data for glyphosate from chronic exposure rodent carcinogenicity studies. Environ Health. 2020;19:118. doi:10.1186/s12940-020-00574-1

96. Wang L, Deng Q, Hu H, et al. Glyphosate induces benign monoclonal gammopathy and promotes multiple myeloma progression in mice. J Hematol Oncol. 2019;12(1):70. doi:10.1186/s13045-019-0767-9

97. Ericsson M, Hardel L, Carlberg M, Åkerman M. Pesticide exposure as risk factor for non-Hodgkin lymphoma including histopathological subgroup analysis. Cancer. 2008;123(7):1657-63. doi:10.1002/ijc.23589

98. Zhang L, Rana I, Shaffer RM, et al. Exposure to glyphosate-based herbicides and risk for non-Hodgkin lymphoma: A meta-analysis and supporting evidence. Mutat Res. 2019;781:186-206. doi:10.1016/j.mrrev.2019.02.001 
99. Prasad S, Srivastava S, Singh M, Shukla Y. Clastogenic Effects of Glyphosate in Bone Marrow Cells of Swiss Albino Mice. J Toxicol. 2009;2009:308985. doi: 10.1155/2009/308985

100. Avila-Vazquez M, Difilipol FS, Lean BM, et al. Environmental exposure to glyphosate and reproductive health impacts in agricultural population of Argentina. Journal of Environmental Protection. 2018;9(3):83267. doi:10.4236/jep.2018.93016

101. de Souza JA, Laureano-Melo R, herai RH, et al. Maternal glyphosate-based herbicide exposure alters antioxidant-related genes in the brain and serum metabolites of male rat offspring. Neurotoxicology. 2019;74:121-131. doi:10.1016/j.neuro.2019.06.004

102. Nozdrenko D, Abramchuk O, Prylutska S. Analysis of Biomechanical Parameters of Muscle Soleus Contraction and Blood Biochemical Parameters in Rat with Chronic Glyphosate Intoxication and Therapeutic Use of C60 Fullerene. Int J Mol Sci. 2021 May 7;22(9):4977. doi: 10.3390/ijms22094977.

103. Mesnage R, Renney G, Seralini GE, et al. Multiomics reveal non-alcoholic fatty liver disease in rats following chronic exposure to an ultra-low dose of Roundup herbicide. Sci Rep. 2017;7:39328. doi:10.1038/srep39328

104. Mertens M, Hoss S, Neumann G, et al. Glyphosate, a chelating agent-relevant for ecological risk assessment? Environ Sci Pollut Res Int. 2018;25(6):5298-5317. doi:10.1007/ s11356-017-1080-1

105. Tarazona JV, Court-Marques D, Tiramani M. Glyphosate toxicity and carcinogenicity: a review of the scientific basis of the European Union assessment and its differences with IARC Arch Toxicol. 2017;91(8):2723-2743. doi: 10.1007/s00204-017-1962-5

106. Benbrook CM. How did the US EPA and IARC reach diametrically opposed conclusions on the genotoxicity of glyphosate-based herbicides? Environmental Sciences Europe. 2019;31(2). doi:10.1186/s12302-018-0184-7

107. Aune D, Giovanucci E, Boffetta P, et al. Fruit and vegetable intake and the risk of cardiovascular disease, total cancer and all-cause mortality-a systematic review and dose-response meta-analysis of prospective studies. Int J Epidemiol. 2017;46(3):1029-1056. doi:10.1093/ije/dyw319

108. USDA Forest Service. Glyphosate Dangers. Retrieved from https://www.fs.usda.gov/nfs/11558/www/nepa/96158_FSPLT3_3996064.pdf

109. Howard J. Minimum Latency \& Types or Categories of Cancer. October 17, 2012, Revised: May 1, 2013. Revised: November 7, 2014. World Trade Center Health Program

110. Wu J, Deng W, Li S, Yang X. Advances in research on ACE2 as a receptor for 2019-nCoV. Cellular and Molecular Life Sciences https://doi.org/10.1007/s00018-020-03611-x

111. Fallon JR, Taylor AB. (15 May 2013) Protein Synthesis in Neurons. Retrieved from https://doi.org/10.1002/9780470015902.a0000050.pub2

112. Rhea EM, Logsdon AF, Hansen KM, et al. The S1 protein of SARS-CoV-2 crosses the blood-brain barrier in mice. 16 December 2020. (intravenously injected radioiodinated S1 
(I-S1) readily crossed the blood-brain barrier in male mice)

113. Nafee N, Gouda N. Nucleic Acids-based Nanotherapeutics Crossing the Blood Brain Barrier Curr Gene Ther. 2017;17(2):154-169. doi: 10.2174/1566523217666170510155803.

114. Boado RJ, Pardridge WM. The brain-type glucose transporter mRNA is specifically expressed at the blood-brain barrier. Biochem Biophys Res Commun. 1990 Jan 15;166(1):174-9. doi: 10.1016/0006-291x(90)91927-k

115. Radcliffe S. (August 25, 2021). Health News. Healthline. FDA Is Reportedly Looking Again at Heart Inflammation Linked to Moderna Vaccine. Retrieved from https:// www.healthline.com/health-news/fda-to-add-warning-on-mrna-covid-19-vaccines-about-rareheart-related-side-effect

116. Polack FP, Thomas SJ, Kitchin N, et al. Safety and Efficacy of the BNT162b2 mRNA Covid-19 Vaccine. N Engl J Med. 2020;383:2603-15. DOI:10.1056/NEJMoa2034577 


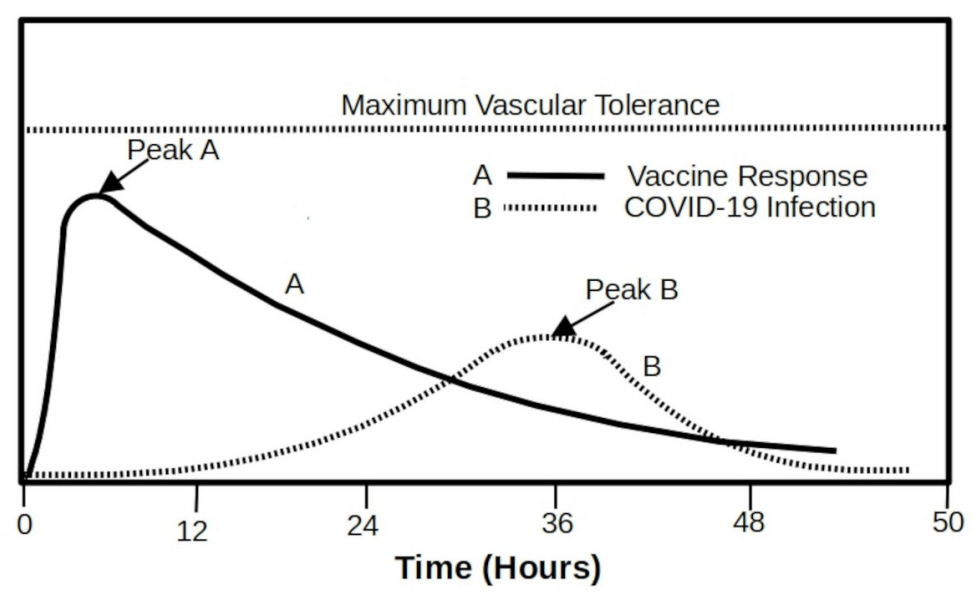

FIG. 1. An mRNA vaccine can generate a massive number of "antigens" as shown in Cure A, while a natural infection starts with a very small number of viral copies. Due to immune responses, the viral number is not in a condition to reach a large population rapidly.

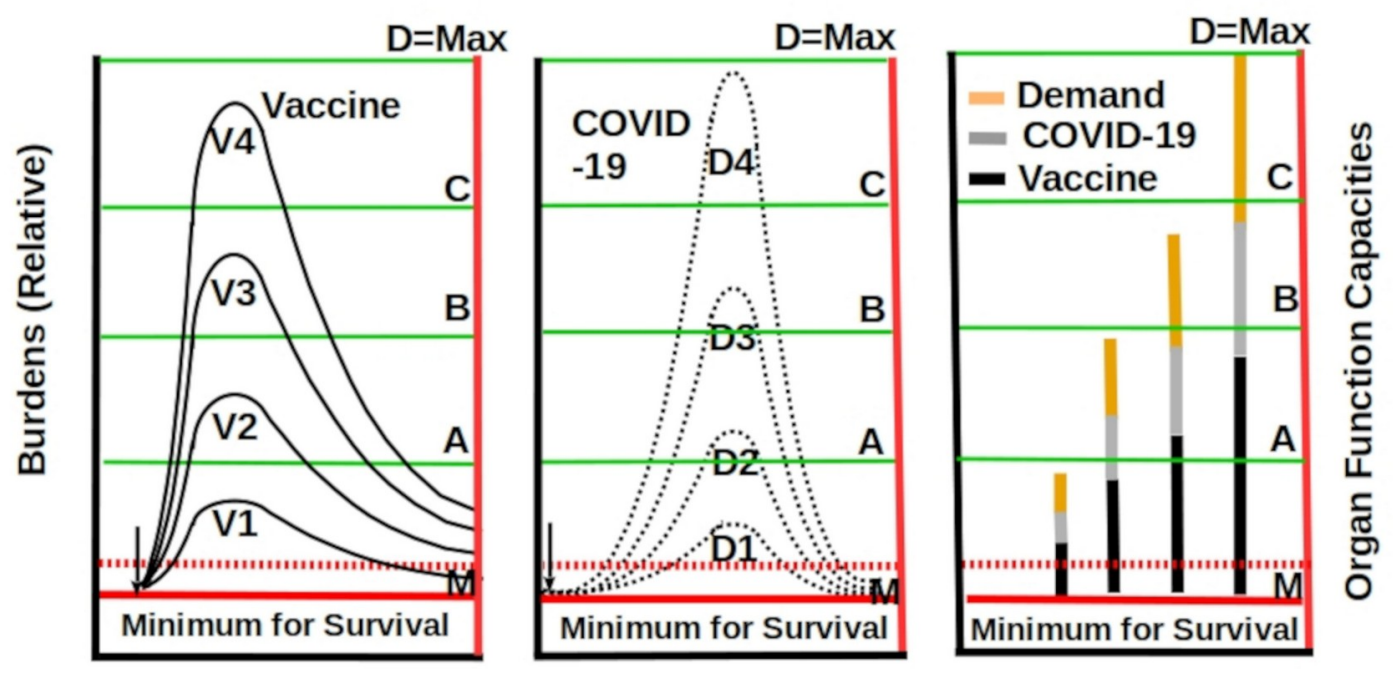

FIG. 2. Personal vital organs function capacities are indicated by line $M, A, B, C$ and $D$ with $M$ as the minimum for sustaining life and $D$ as the maximum. $A$ young and healthy person has huge unused functional capacities. Vaccine burden is shown in the left diagram, infection burden is shown in the middle diagram, and the right diagram shows the combination of vaccine, COVID-19 infection and life activity burdens. A person's ability to survive from the vaccine or infection depends on the total functional capacities. The person can survive if the total burden from all sources is within the organ functional capacities. 


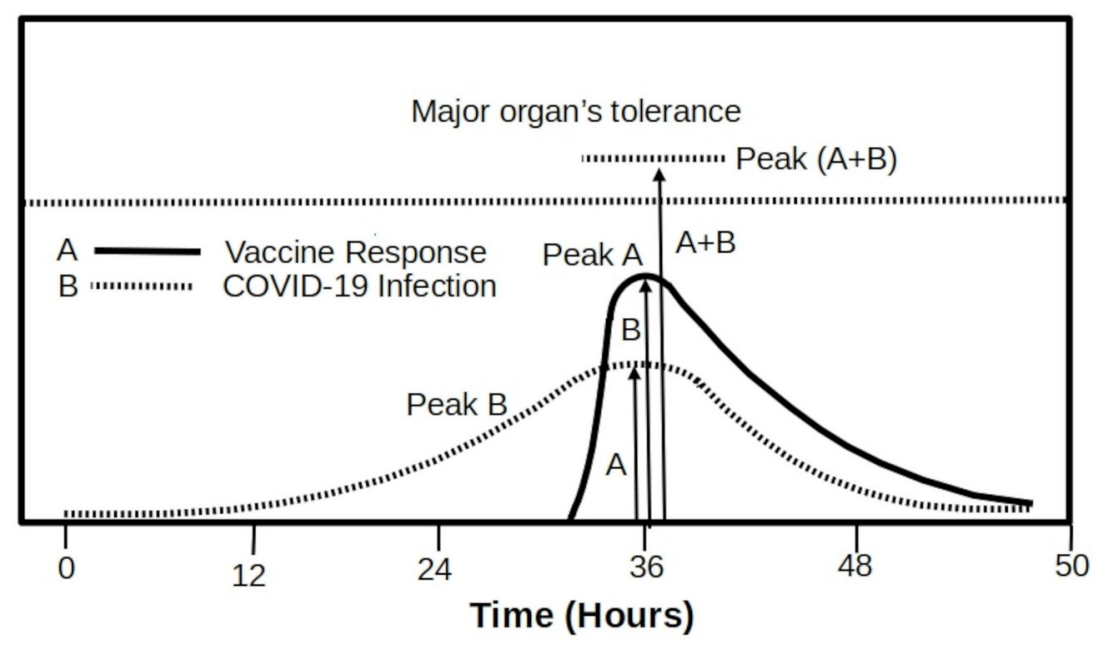

FIG. 3. When the peak of the vaccine response (A) and peak of COVID-19 infection (B) happen to be in overlap, they will generate much severer adverse reactions indicated as Peak $A+B$. The total burden may exceed what the heart could tolerate and thus cause death.

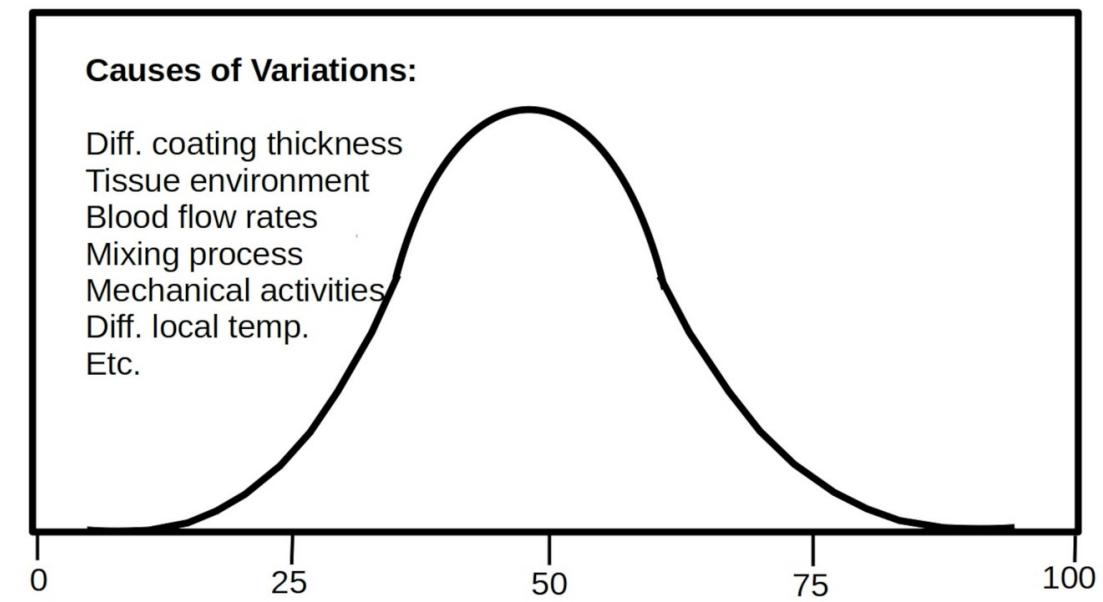

Particles Relative Travel Distances

FIG. 4. The mRNA particles have different protective coatings and some of them can travel longer distances while others travel short distances. They can survive for different times in blood. The variations in traveling distance or survival time are also caused by variations in blood circulation, tissue structure, tissue mechanical features, chemical environment, temperature, etc. 


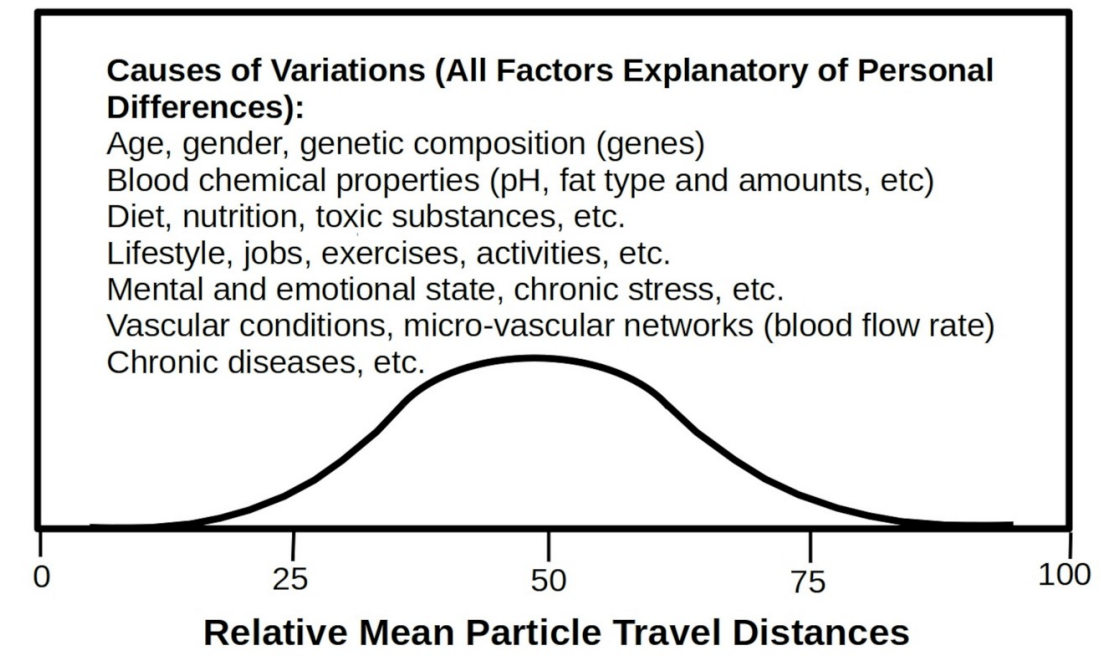

FIG. 5. Mean traveling distances or mean survival times of mRNA particles differ in different persons and may follow the normal distribution (Relative traveling distance or survival time versus means' frequency). Due to complexity, such a mean is only an imagined number. The mean for a person depends on age, gender, genetic conditions, blood compositions, diet, nutrition, toxic substances, personal activities, mental condition, vascular condition, chronic diseases, etc.

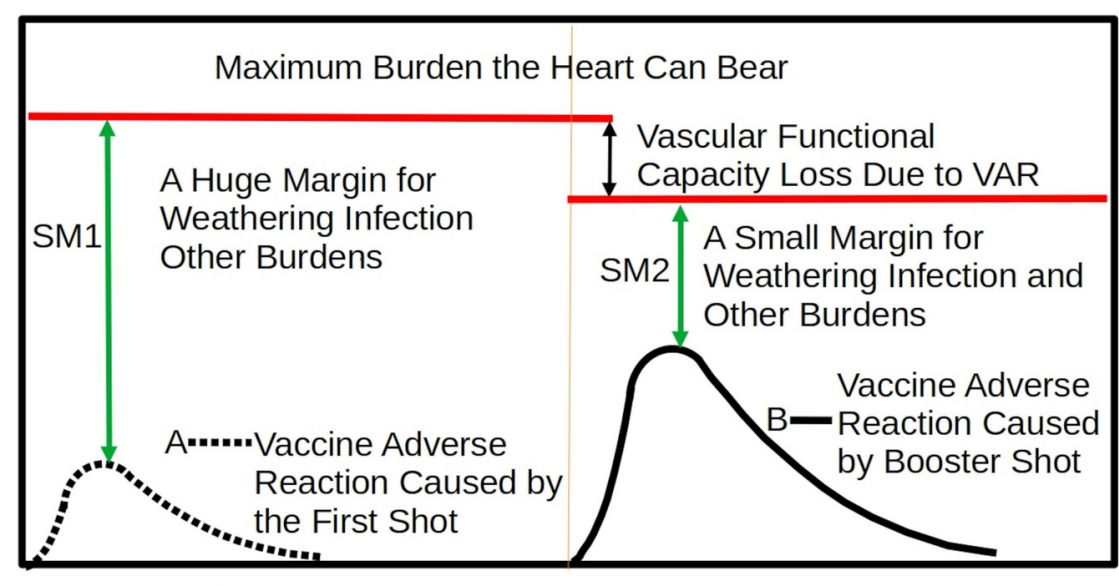

Time

Time

FIG. 6. The first vaccine shot may generate a small vaccine adverse reaction (VAR) peak. The first shot may reduce vital functional capacities and also activate the immune system for fighting the "antigen". The second shot will make this VAR peak much larger. In the initial shot, the body has huge surplus functional capacities for weathering the cytokine storm and other life activity burdens. The booster shots will dramatically reduce the body's ability to weather infection, vaccine and life-activity burdens. The person's functional capacity margin for survival will decline from SM1 to SM2. By keeping being vaccinated, functional capacity margin will approach zero. 